bioRxiv preprint doi: https://doi.org/10.1101/2021.10.05.460818; this version posted October 6, 2021. The copyright holder for this preprint (which was not certified by peer review) is the author/funder, who has granted bioRxiv a license to display the preprint in perpetuity. It is made available under aCC-BY-NC-ND 4.0 International license.

\title{
A proximal-to-distal survey of healthy adult human small intestine and colon epithelium by single-cell transcriptomics
}

Joseph Burclaff ${ }^{1,2,9}$, R. Jarrett Bliton ${ }^{3,9}$, Keith A Breau ${ }^{4}$, Meryem T Ok ${ }^{3}$, Ismael Gomez-Martinez ${ }^{4}$, Jolene S Ranek $^{5}$, Aadra P Bhatt ${ }^{1,2,6}$, Jeremy E Purvis ${ }^{5,7}$, John T Woosley ${ }^{8}$, Scott T Magness ${ }^{1,2,3,4,6^{*}}$

${ }^{1}$ Department of Medicine, University of North Carolina at Chapel Hill, Chapel Hill, North Carolina

${ }^{2}$ Center for Gastrointestinal Biology and Disease, University of North Carolina at Chapel Hill, Chapel Hill, North Carolina

${ }^{3}$ Joint Department of Biomedical Engineering, University of North Carolina at Chapel Hill/North Carolina State University, Chapel Hill, North Carolina

${ }^{4}$ Department of Cell Biology and Physiology, University of North Carolina at Chapel Hill, Chapel Hill, North Carolina

${ }^{5}$ Curriculum in Bioinformatics and Computational Biology, University of North Carolina at Chapel Hill, Chapel

Hill, North Carolina

${ }^{6}$ Lineberger Comprehensive Cancer Center, University of North Carolina at Chapel Hill, Chapel Hill, North

Carolina

${ }^{7}$ Department of Genetics, University of North Carolina at Chapel Hill, Chapel Hill, North Carolina

${ }^{8}$ Department of Pathology and Laboratory Medicine, University of North Carolina School of Medicine, Chapel

Hill, NC

${ }^{9}$ These authors contributed equally

*Correspondence: magness@med.unc.edu

All authors declare no conflicts of interest

Author Contributions:

STM designed and supervised the project

JB, RJB, KAB, MTO, IG, STM obtained and analyzed data

$\mathrm{RJB}$ and KAB performed computational analysis

JB, RJB, STM wrote the manuscript

JTW analyzed histology slides

APB and JSR provided intellectual contributions

JSR and JEP reviewed computational analyses

All authors reviewed the final manuscript

All data will be available in the NCBI Gene Expression Omnibus: accession number GSE185224

Python Scripts allowing for main steps of our analysis to be performed will be available on GitHub

Abbreviations Used:

SI: Small intestine; scRNAseq: single-cell RNA sequencing; AC: Ascending Colon; TC: Transverse Colon; DC:

Descending Colon; PC: Paneth Cell; FAE: Follicle Associated Epithelium; EEC: Enteroendocrine Cell; GC:

Goblet Cell; DEG: Differentially Expressed Genes; ISC: Intestinal Stem Cell; TA: Transit Amplifying; ACC:

Absorptive Colonocyte; AE: Absorptive Enterocyte; PAGA: Partition-based Graph Abstraction; M-cell: Microfold Cell; Gl: Gastrointestinal; crGC: Crypt-Resident Goblet Cell; icGC: Inter-Crypt Goblet Cell 


\section{Abstract}

Background and Aims: Single-cell transcriptomics offer unprecedented resolution of tissue function at the cellular level, yet studies analyzing healthy adult human small intestine and colon are sparse. Here, we present single-cell transcriptomics covering the duodenum, jejunum, ileum, and ascending, transverse, and descending colon from 3 humans.

Methods: 12,590 single epithelial cells from three independently processed organ donors were evaluated for organ-specific lineage biomarkers, differentially regulated genes, receptors, and drug targets. Analyses focused on intrinsic cell properties and capacity for response to extrinsic signals along the gut axis across different humans.

Results: Cells were assigned to 25 epithelial lineage clusters. Human intestinal stem cells (ISCs) are not specifically marked by many murine ISC markers. Lysozyme expression is not unique to human Paneth cells (PCs), and PCs lack expression of expected niche-factors. BEST4 ${ }^{+}$cells express NPY and show maturational differences between SI and colon. Tuft cells possess a broad ability to interact with the innate and adaptive immune systems through previously unreported receptors. Some classes of mucins, hormones, cell-junction, and nutrient absorption genes show unappreciated regional expression differences across lineages. Differential expression of receptors and drug targets across lineages reveals biological variation and potential for variegated responses.

Conclusions: Our study identifies novel lineage marker genes; covers regional differences; shows important differences between mouse and human gut epithelium; and reveals insight into how the epithelium responds to the environment and drugs. This comprehensive cell atlas of the healthy adult human intestinal epithelium resolves likely functional differences across anatomical regions along the gastrointestinal tract and advances our understanding of human intestinal physiology.

Keywords: scRNAseq; Cell Atlas; Intestinal Stem Cell; Paneth cell; BEST4

\section{Introduction}

Colloquially called the 'gut', the small intestine (SI) and colon are distinct organs with overlapping and unique roles in maintaining health. A monolayer of epithelium lines the gut lumen, comprised of stem and differentiated cells that renew the epithelium each week ${ }^{1}$. Broad health conditions develop at the intestinal epithelium, caused by pathological mucosal immunity ${ }^{2}$, dysregulation of carefully orchestrated cell-cell signaling, or disrupted synergy between stem cell-driven self-renewal and production of differentiated lineages. This complexity is little understood at the cellular level.

The generalized function of the gut epithelium is maintaining barrier function, absorbing nutrients, and regulating water. Cellular roles include ion balance, hormone production, mucus production, and signaling through the luminal-epithelial-immune axis. While physiological functions differ across the gut length, how lineages differ along the SI-colon axis is poorly understood. Whether adult gut epithelial lineages adopt regional fates and functions is a central question of human gut physiology and disease.

Single-cell RNA sequencing (scRNAseq) approaches have provided unprecedented transcriptomic resolution of cells and revealed unappreciated cellular heterogeneity. Studies in mouse intestines ${ }^{3-5}$ led to human scRNAseq studies analyzing fetal gut development ${ }^{6-8}$ and adult colonic ${ }^{9-12}$, ileal $^{13-15}$, and duodenal ${ }^{16}$ epithelium. To date, one study compares adult human ileum and regionally-unspecified colon ${ }^{13}$, and one recent report compiles samples from across the gut yet has limited epithelial analysis ${ }^{17}$. Several human gut regions have sparse scRNAseq analysis available, with no studies analyzing regional differences within SI or colon. Addressing these gaps requires technically and logistically challenging approaches.

Here we comprehensively survey adult human gut epithelium using transplant-grade organs. scRNAseq libraries were prepared from epithelial cells from duodenum, jejunum, ileum, and ascending- (AC), transverse- (TC), and descending- (DC) colon from three donors. This robust cellular library avoids intra-donor batch effects and allows for observations between individual patients. Using this dataset, we probe understudied human lineages including Paneth cells (PCs), SI BEST4 ${ }^{+}$cells, and Follicle Associated Epithelium (FAE). We define comprehensive transcriptional signatures for lineages across the entire gut, highlight differences between human and mouse markers, and generate regional atlases of functional gene 
bioRxiv preprint doi: https://doi.org/10.1101/2021.10.05.460818; this version posted October 6, 2021. The copyright holder for this preprint (which was not certified by peer review) is the author/funder, who has granted bioRxiv a license to display the preprint in perpetuity. It is made available under aCC-BY-NC-ND 4.0 International license.

families across the proximal-to-distal axis. We further probe how lineages might be affected by extrinsic signaling by mapping receptor families and analyzing primary gene targets of approved drugs.

\section{Methods}

\section{Donor Selection}

Human donor intestines were received from HonorBridge (Durham, NC) with acceptance criteria: age $\leq 65$ years, brain-dead only, HIV(-), hepatitis(-), syphilis(-), tuberculosis(-), COVID-19(-), and no bowel surgery, severe abdominal injury, cancer, or chemotherapy. Pancreas donors were excluded to avoid duodenum loss. UNC IRB determined this study does not constitute human subjects research.

\section{Tissue processing}

Intestines were transported on ice in University of Wisconsin Solution. Tissue dissection began within eight hours of cross-clamping. Fat/connective tissue were trimmed and intestinal regions separated: duodenum (most-proximal $20 \mathrm{~cm}$ ); jejunum/ileum splitting remaining SI; colon split into thirds for AC/TC/DC. Two $3 \times 3 \mathrm{~cm}$ mucosectomies were isolated from the center of each region for dissociation.

Mucosectomies were incubated in $10 \mathrm{mM}$ NAC in dPBS at room temperature for 30 min to remove mucus, then washed in ice-cold Chelating Buffer ${ }^{18}+100 \mu \mathrm{mol} / \mathrm{L}$ Y-27632. Tissues were incubated in Chelating Buffer with $2 \mathrm{mmol} / \mathrm{L}$ EDTA and $0.5 \mathrm{mmol} / \mathrm{L}$ DTT, then shaken to remove crypts. High-yield colon shakes were pooled, with SI shakes pooled to approximate 1:1 villus to crypt tissue by cell mass. Crypts and villi were dissociated to single cells using $4 \mathrm{mg} / \mathrm{mL}$ Protease VIII in dPBS + Y-27632 on ice for $\sim 45 \mathrm{~min}$ with trituration via a P1000 micropipette every $10 \mathrm{~min}$. Cells was checked under a light microscope then filtered.

\section{Sample preparation}

Single cells were washed with dPBS + Y-27632, resuspended in Advanced DMEM/F12 + 1\% Bovine Serum Albumin + Y-27632, then stained with AnnexinV-APC (1:100) and one TotalSeq Anti-Human Hashtag Antibody $(1: 100)$ per region to track all six regions with a single library preparation ${ }^{19}$. Cells were washed and resuspended in AdvDMEM $+1 \%$ BSA + Y-27632 for sorting on a Sony Cell Sorter SH800Z to enrich for live single epithelial cells. 25,000 cells were collected for each region, then regions were combined presequencing. Library prep was performed with the Chromium Next GEM Single Cell 3' GEM, Library \& Gel Bead Kit v3.1 (PN-100012). Sequencing was performed on an Illumina NextSeq 500.

\section{Data preparation and Hashtag Calling}

Harmony (v0.0.5) was used to integrate the top 40 principal components from each dataset for clustering and visualization ${ }^{20}$. Leiden clustering was initialized with a $\mathrm{kNN}$ graph ( $\mathrm{k}=10$ neighbors) and a Leiden resolution of $0.92^{21}$ to resolve most expected physiological lineages. UMAPs were initialized with PAGA of identified Leiden clusters $^{21,22}$, then non-epithelial EPCAM-negative lineages were eliminated. Regional hashtag deconvolution followed published methods: raw hashtag read counts were normalized using centered log ratio transformation followed by k-medoid clustering of hashtag read counts, with $k=6$ medoids for donor 1 and $k=7$ medoids for donors 2 and $3^{19}$. Hashtag noise distributions were determined by removing the highest-expressing cluster, then fitting a negative binomial distribution to the remaining cells. Cells were considered positive for a hashtag with counts above the distribution's $99^{\text {th }}$ percentile $(p<0.01)$ threshold. Cells positive for multiple hashtags were excluded as likely doublets.

\section{Results}

\section{Sample processing}

We define SI and colon as 'organs' and duodenum, jejunum, ileum, AC, TC, and DC as 'regions'. Intestinal tracts were obtained from three organ donors (Fig. 1A,S1) with no history of cancer or intestinal disease, and healthy mucosa was verified by a pathologist (Fig. S2). Tissue was resected from each donor (Fig. 1A, Fig. S2) then epithelium was dissociated to single cells using cold protease to preserve RNA integrity. Each region's cells were stained with Cell Hashtag antibody-oligo conjugates ${ }^{8,19}$ to multiplex regions for library 
preparation and sequencing, avoiding intra-donor batch effects and reducing cost (Fig. S4). FACS excluded dead cells and doublets (Fig. S3) prior to sequencing. After filtering for quality, transcriptional readouts for 12,590 total cells $(4,330,4,465$, and 3,795 cells/donor) were obtained (Fig S1,S5).

Donor sequencing datasets were individually processed then combined, with principal components integrated with Harmony ${ }^{20}$ to minimize donor-specific differences prior to dimensional reduction and Leiden clustering $^{21}$. Most lineages formed distinct SI/colon-specific clusters, suggesting functional differences by location. No organ-specific clustering occurred for enteroendocrine cells (EECs) and secretory progenitors (Fig. S6). One cluster expressed PC and goblet cell (GC) markers, so sub-clustering resolved these lineages (Fig. S6). Our final dataset identifies all lineages by organ along with rare FAE (Fig. 1B). The integrated dataset shows overlapping cell distributions from each donor and region within all major lineages, demonstrating that post-sequencing hashtag deconvolution preserves transcriptomic features across samples and batches (Fig. 1C-E).

To define significant marker genes across the gut, we calculated differentially expressed genes (DEGs) in each lineage versus all other cells from each organ. We identified DEGs consistently enriched across all three donors and the combined dataset. Through this rigorous statistical evaluation, we developed a unique signature for all major lineages across the human SI and colon epithelium, a previously unavailable resource (Fig. 1F,G, Table S1,S2).

\section{Proliferative Cells}

We found human Intestinal Stem Cells (ISCs) differentially expressed classical markers LGR5, ASCL2, SLC12A2, and RGMB (Fig. 2A,B) ${ }^{23-25}$. Though enriched, SMOC2 ${ }^{26}$ was not a DEG in SI ISCs, as PCs express higher levels (see PCs). While in situ hybridization showed OLFM4 marks human SI and colonic ISCs ${ }^{27}$, our data indicate significantly higher levels of OLFM4 in SI ISCs, with colonic OLFM4 higher in transit amplifying (TA) cells and early absorptive colonocytes (ACCs) (Fig. 2A,B). This concurs with mouse, where Olfm4 transcripts marked SI but not colon ISCs ${ }^{24}$. Notably, RARRES2 was enriched in colon ISCs, with low expression in SI ISCs (Fig. 2B). We found no gut-related literature on this retinoid response gene, providing an intriguing target for future studies.

We constructed a comprehensive human ISC signature. SI ISCs had 68 DEGs compared to other clusters across SI regions for all three donors, whereas colon ISCs displayed 109 DEGs (Table S1, Fig. S7). To define a human ISC transcriptional signature spanning SI and colon, we identified 46 DEGs enriched in ISCs from both organs (Table S2). This signature includes classical ISC markers along with 30 ribosomal genes. While ribosomal genes are less abundant in murine ISC signatures ${ }^{26,28,29}$, this is consistent with literature describing ribosomal control of transcriptional dynamics in other stem cells ${ }^{30-32}$. To identify ISC DEGs conserved between human and mouse, we compared our 68-gene SI ISC signature with a mouse signature with 344 human homologs ${ }^{26}$. Surprisingly, only 11 genes overlapped between the human and mouse signatures (Fig. 2C), although it is unclear whether this reflects species differences or the higher resolution and stringency of our computational approach. Conserved genes included classical markers: LGR5, OLFM4, ASCL2, RGMB, SLC12A2, and MYC; genes with known ISC function: RNF43, ZBTB38, VDR, and CDK6; and one gene not described in ISC literature: TRIM24, a gene involved in p53 degradation. These SI, colon, and full-gut ISC signatures underline key similarities and differences in proximal-distal human ISCs.

TA cells are classically defined by high proliferation and location above ISCs in the intestinal crypt $^{9,33}$.Leiden clustering separated SI TA cells undergoing S/G2 cell-cycle phases (TA) and M-phase (TA2) (File S1,S2). We evaluated DEGs between SI TA, TA2, and colon TA cells to define shared TA markers (Fig. 2D). DEGs were involved in cell cycle as well as in mitochondrial biogenesis and rRNA processing, consistent with increased mitochondrial load and translation levels seen as stem cells differentiate in various systems ${ }^{30,34-}$ 36. Several organ-specific markers of differentiated lineages (Fig. S8) were unexpectedly enriched in their respective SI or colon ISC and TA populations (Fig. 2E), hinting that ISCs are already transcriptionally primed for organ-specificity, instead of existing in a naïve, pan-intestinal state. This is consistent with rodent studies showing adult SI ISCs produce daughter cells specific to their originating organ when engrafted into alternative SI or colon sites ${ }^{37,38}$. Studies defining region/organ-specific chromatin or active transcriptomic differences in 
bioRxiv preprint doi: https://doi org/10.1101/2021.10.05.460818; this version posted October 6, 2021. The copyright holder for this preprint (which was not certified by peer review) is the author/funder, who has granted bioRxiv a license to display the preprint in perpetuity. It is made available under aCC-BY-NC-ND 4.0 International license.

ISCs were not found; thus, these genes may prove useful for studying differentiation and chromatin dynamics in early fate-determination.

Trajectory analyses computationally investigate lineage transitions, with intestinal analyses primarily using mouse data ${ }^{39-42}$. We used Partition-based Graph Abstraction (PAGA), which estimates connectivity between clusters, to infer connections between proliferative crypt-based lineages and differentiated populations $^{22}$. Absorptive enterocytes (AEs) and ACCs arise nearly exclusively from ISCs and TA cells ${ }^{15}$. The secretory progenitor population arises from ISCs and TA cells and gives rise to PCs, GCs, and EECs (Fig. $2 F, G)$. Interestingly, tuft cells appear to derive from secretory progenitors in colon but not SI, consistent with murine findings ${ }^{39}$. Conversely, SI BEST4 ${ }^{+}$cells apparently arise from secretory progenitors while colon BEST4 ${ }^{+}$ cells connect to TA cells, agreeing with absorptive and secretory functions ascribed to this novel lineage ${ }^{12,16}$.

Predicted regional cell cycle phase distributions ${ }^{43}$ were analyzed in ISCs, TA cells, and secretory progenitors (Fig. 2H-J). ISCs showed expected high $\mathrm{G} 1$ and S phase representation across regions ${ }^{13,44}$, while highly-proliferative TA cells largely existed in S and G2/M. TC showed a significantly lower proportion of TA cells in G2/M than jejunum, with similar regional differences in rodents ${ }^{45,46}$, but biological implications are unknown. Secretory progenitors had notably different distributions, with $S$ phase proportions increasing proximally-to-distally and higher G1 proportion than TA cells (Fig. S1). Since secretory progenitors differentiate into specialized lineages, elongated G1 may allow for additional reception of differentiation factors, as stem cells are most receptive to such cues during $\mathrm{G} 1^{47}$.

\section{Paneth Cells}

Murine PCs play important niche-supporting and antimicrobial roles ${ }^{48}$, yet little scRNAseq analysis covers human PCs. Our dataset includes 49 PCs representing all SI regions across three donors, 10-times more than analyzed in recent literature ${ }^{16}$. PCs were defined using DEFA5, DEFA6, ITLN2, and PLA2G2A (Fig. 3A). Surprisingly, Lysozyme ( $L Y Z$ ), an important murine PC marker, was expressed higher in SI BEST4 ${ }^{+}$cells and $\mathrm{FAE}$, with measurable tuft cell expression, making $L Y Z$ an imprecise human $\mathrm{PC}$ marker (Fig. 3B). This is consistent with $L Y Z$ expression in organoids derived from a fetal human stage too young to form $\mathrm{PCs}^{6}$. Since PCs cluster alongside GCs and share $L Y Z$ expression with BEST4 ${ }^{+}$cells, classical PC markers were plotted to confirm PC identify (Fig. 3C). Importantly, our data indicate the cells described as PCs in a recent scRNAseq publication $^{13}$ are BEST4 ${ }^{+}$cells, with high $L Y Z$, SPIB, BEST4, and CA7. Similarly, the reported colonic 'PanethLike Cells' in the study are likely BEST4 ${ }^{+}$cells unrelated to PCs other than $L Y Z$ expression. The rarity of PCs $\left(<1 \%\right.$ of our dataset and others $\left.{ }^{16}\right)$ and divergence of PC and BEST4 markers highlights the precise lineage attribution needed when defining human PCs.

We next probed whether human PCs express ISC niche factors. Murine PCs express Wnt3, Wnt11, Tgfa, Egf, DIl1, Rspo1, and DI/4 40,48-50, but one report shows human PCs express no WNT3/11 ${ }^{16}$. Our data confirm this and demonstrate no measurable EGF or RSPO1 and minimal TGFA. While human PCs express DLL1 and DLL4, both are higher in secretory progenitors (Fig. 3D). We found no members of any major intestinal growth factor family broadly enriched in PCs (Fig. S9), suggesting human PCs are not major nichesupporting cells. This notion is consistent with non-epithelial sources of WNTs and growth factors in the human niche ${ }^{6,51-53}$, and echoes mouse biology, where PCs are sufficient to support ISCs ${ }^{48}$ yet unnecessary for niche maintenance ${ }^{48,54-56}$.

Unexpectedly, SMOC2, a murine ISC marker, ${ }^{26}$ was expressed highest in PCs, with other mouse ISCrestricted markers ( $L G R 5, A S C L 2, R G M B$ ) higher in human PCs than mouse PCs ${ }^{5}$ (Fig. 3E). ISC-PC doublet artifacts could explain this, however lack of ISC markers (e.g., OLFM4) does not support this hypothesis. LGR5, SMOC2, and ASCL2 are involved in WNT reception ${ }^{23,57-59}$, suggesting human PCs may receive WNT signals instead of providing WNT signals as in mice ${ }^{48}$. PC-unique expression of FZD9 supports a WNTreceptive $\mathrm{PC}$ role ${ }^{60}$ (Fig. S9), with its expected ligand WNT2 ${ }^{61}$ absent in our database yet induced in intestinal inflammation and cancer ${ }^{62-64}$. Mature PCs can dedifferentiate following injury in mice ${ }^{65-67}$, and Ascl2 is required for dedifferentiation in mouse crypts ${ }^{68}$. Thus, expression of these ISC genes may render human PCs more responsive to dedifferentiation cues; however, this needs functional validation. 
A murine subset of colonic GCs termed Paneth-Like Cells or Deep-Crypt Secretory Cells are defined by MUC2, C-KIT, REG4, CD24, EGF, and FZD5 ${ }^{69,70}$. We found only two cells positive for both REG4 and KIT across the 1,252 colon GCs and secretory progenitors (Fig. S9D). Colonic tuft cells expressed higher KIT and CD24 but no REG4. Based on murine-defined markers, we conclude there is no human equivalent to this population. Since human PCs likely perform little niche-supporting activity, namely not producing EGF, human cells with murine PC-like functions may be unnecessary.

Despite striking differences between mouse and human PCs, both supply antimicrobial gene products. Six of the 10 highest-expressed SI antimicrobial peptides are PC-enriched (Fig. 3F). As antimicrobial genes comprise half of human PC DEGs (Table S1), they likely function primarily to protect the ISC-niche from bacterial invasion and regulate microbiota composition ${ }^{71}$.

\section{Follicle-Associated Epithelium}

Rare FAE cells, important for epithelial-immune crosstalk, reside in small puncta throughout the intestines $^{72}$. FAE includes microfold (M)-cells, which transport luminal antigens to immune cells residing within their microfolds ${ }^{73}$. M-cells have almost exclusively been explored in mice ${ }^{74-76}$ or using directed differentiation in vitro $^{77}$, with only one study reporting scRNAseq data from healthy human intestinal M-cells ${ }^{17}$. Our dataset includes a cluster of 19 cells from Donor 2 enriched for M-cell markers ${ }^{78-80}$ and immune cross-talk genes (Fig. S10). Strikingly, several murine M-cell-specific markers were either widely expressed (MARCKSL1, ANXA5, CXCL16) ${ }^{79,81}$ or absent (CCL36, SCG5, TNFRSF9, CCL9, CCL6, PGLYRP1) $)^{73,79,82}$, suggesting species functional differences. With the caveat of including 19 cells from one donor, we defined 145 DEGs (Table S1,S2), finding many FAE-unique genes (Fig. S10). Pathway enrichment analysis implicates these DEGs in immune cell interactions, verifying expected M-cell function (File S3). Differences in chemokines between mouse and human M-cells, with CCL20 the only major shared chemokine, call for enriching for FAE using newly described methods ${ }^{72}$ to probe how human M-cells interact with immune cells.

\section{BEST4 ${ }^{+}$cells}

Recent human single-cell studies describe a novel intestinal lineage, absent in mice, expressing high BEST4, SPIB, and CA7 $7^{12}$, with CFTR in $\mathrm{SI}^{16,17}$ and OTOP2 in colon. Several papers describe colonic BEST4 ${ }^{+}$ cells ${ }^{11,12}$, so we analyze SI BEST4 ${ }^{+}$cells. With BEST4 ${ }^{+}$cell functions largely unknown, DEGs were used to predict physiological roles (Fig. 3G). DEG analysis revealed secreted peptides including GUCA2A and GUCA2B ${ }^{12}$, which can act as pro-hormones effecting a satiety response ${ }^{83-85}$. A previous report showed these genes in $\mathrm{SI}$ and colon BEST4 ${ }^{+}$cells ${ }^{16}$, yet we find both expressed higher in SI than colon BEST4 ${ }^{+}$cells (Fig. $3 \mathrm{H}$ ), indicating a role in satiety signaling in the SI.

We identified two unreported secreted peptides, NPY and BMP3, specifically in SI BEST4 ${ }^{+}$cells. NPY expression was unexpected in intestinal epithelium ${ }^{86}$, and gut $B M P 3$ is largely studied for antitumor roles ${ }^{87,88}$. Diffusion pseudotime, a computational method to define single-cell differentiation trajectories ${ }^{89}$, indicated that NPY, GUCA2A, and GUCA2B expression increased with BEST4 $4^{+}$cell maturation, while BMP3 expression appeared independent of maturation (Fig. 3I). Interestingly, receptors for all four genes are enriched in EECs, suggesting cross-talk between these lineages (Fig. 3H).

Since $N P Y$ is proposed to affect gastrointestinal (Gl) motility ${ }^{90}$ and energy homeostasis ${ }^{91}$, we probed if NPY correlated with genes induced following meals. Looking across SI regions for each individual donor, we found a strong positive correlation between SI BEST4 ${ }^{+}$cell NPY and AE expression of $S I(\mathrm{R}=0.82)$ and APOA4 $(R=0.86)$, which are induced in mice by dietary sugar ${ }^{92}$ and fat $^{93}$ (Fig. 3J). We found further positive correlations with $A E$ genes involved in dietary metabolism (Table S3), and negligible correlation with housekeeping genes ACTB $(\mathrm{R}=-0.22)$ or GAPDH $(\mathrm{R}=-0.08)$. Thus, NPY expression in SI BEST4 ${ }^{+}$cells may be induced by luminal contents. Further DEGs from SI BEST4 ${ }^{+}$cells included adrenergic and cholinergic neurotransmitter receptors involved in intestinal motility ${ }^{94}, A D R A 2 A$ and $C H R M 3$ (Table S1), supporting that SI $\mathrm{BEST}^{+}$cells may regulate intestinal motility following meals.

$\mathrm{BEST}^{+}$cells likely absorb dietary heavy metals. Metallothionein expression has been implicated in colonic BEST4 ${ }^{+}$cells ${ }^{12}$, yet we find seven members of this family, known to bind heavy metals and protect 
bioRxiv preprint doi: https://doi org/10.1101/2021.10.05.460818; this version posted October 6, 2021. The copyright holder for this preprint (which was not certified by peer review) is the author/funder, who has granted bioRxiv a license to display the preprint in perpetuity. It is made available under aCC-BY-NC-ND 4.0 International license.

against toxicity ${ }^{95-97}$, specifically enriched in SI BEST4 ${ }^{+}$cells (Fig 3K). Unique expression of STEAP2, a metalloreductase for copper and iron ${ }^{98}$, supports a role for SI BEST4 ${ }^{+}$cells in maintaining SI homeostasis for many metal ions ${ }^{97-99}$. SI BEST4 ${ }^{+}$cells express endocytosis effector genes DNM1 and DNM2 (Fig. 3K), supporting an absorptive role for these cells. Our data indicate BEST4+ ${ }^{+}$cells perform diverse roles within the intestinal epithelium, laying the groundwork for functional studies.

\section{Tuft Cells}

Tuft cells are chemosensory epithelial cells which regulate type-2 immune reactions in the intestinal epithelium through pathogenic metabolite detection and classical taste signal transduction pathways ${ }^{100-102}$. Together, these initiate tuft cell IL-25 release ${ }^{103-105}$. SI and colon tuft cells share many classical markers ${ }^{16,106}$ (Fig. 4A, Table S1,S2). DCLK1, a key murine marker ${ }^{105}$, was not observed. Interestingly, SUCNR1, a G-protein coupled receptor mediating SI IL-25 release ${ }^{107}$, was negligible in colon, suggesting SI and colon tuft cells differentially detect and respond to luminal succinate-producing pathogens (Fig. 4B,C). Instead, colonic tuft cells likely respond to umami-chemosensory cues, such as microbe-derived free amino acids, as they express heterodimeric umami taste receptor subunits TAS1R1 and TAS1R3 (Fig. 4B,C) ${ }^{108}$. We further analyzed downstream taste signal transduction genes, finding $\mathrm{SI}$ and colon tuft cells enriched in critical pathway components (GNB1, GNG13, ITPR2, TRPM5) ${ }^{100,101}$, with SI-specific GNAT3, a G-protein alpha subunit, which likely activates $P D E 4 D$ to decrease intracellular $\mathrm{CAMP}_{\mathrm{cGMP}}{ }^{109}$ (Fig. 4B). This suggests human SI tuft cells have varied responses to succinate-producing microbes (e.g., N. brasiliensis), whereas colonic tuft cells may respond more broadly to other microbial taxa.

Beyond triggering type-2 immunity, tuft cell DEGs allow broad interaction with the adaptive and innate immune systems. Tuft cells express DEGs involving ubiquitin-mediated proteasome degradation, including SCF complex components (SKP1, CUL3, FBXO32, RBX1) which initiate processing of exogenous antigens for presentation $^{110,111}$, as well as genes for the MHC1 antigen presentation complex (Fig. 4D). This suggests tuft cells may interact with the adaptive immune system following luminal stimuli. Human tuft cells also uniquely express previously unappreciated Toll-Like Receptors -TLR9, TLR5, and TLR4 - which bind bacterial and viral DNA, bacterial flagellin, and lipopolysaccharide (LPS), respectively ${ }^{112-114}$ (Fig. 4D). Expression of the LPS coreceptor CD14 across tuft cells (Fig. 4D) supports a novel role in bacterial-related immune responses ${ }^{112}$.

Tuft cells exhibit possible auto-regulatory mechanisms for these pathogen-response pathways. Tuft cells express heterodimeric IL-25-specific receptor components IL17RA and IL17RB (Fig. 4D) which may create a positive feedback loop to amplify IL-25 signaling, as in keratinocytes ${ }^{115}$. Tuft cells may also autoregulate their LPS response through SIGIRR, which negatively regulates TLR4-LPS signaling ${ }^{116-118}$. These implicate tuft cells as dynamic sentinels linking luminal contents to the immune system.

Consistent with a role regulating gut pathogens, tuft cells produce $L Y Z, P R S S 3$, and DEFB1 antimicrobial peptides in the SI (Fig. 3F) and six of the top ten antimicrobial peptides in the colon, without PCs present (Fig. 4E). Finally, human and murine tuft cells both produce neuro- and immunomodulatory compounds. We find genes necessary for acetylcholine synthesis (CHAT, SLC18A3/VACHT), communication with neurons $(N C A M 1)^{119}$, and enzymes involved in eicosanoid production, namely cysteinyl leukotrienes (ALOX5 and ALOX5AP) and Prostaglandin $\mathrm{D}_{2}$ (PTGS1 and HPGDS), which broadly regulate inflammation ${ }^{120}$ (Fig. 4F). Altogether, these genetic analyses indicate tuft cells regulate luminal microbes, communicate with the nervous system, and effect systemic immune responses.

\section{Goblet Cells}

GCs produce membrane-bound and secreted mucin glycoproteins that lubricate the gut, act in signaling, support commensal bacteria, and form the protective mucus barrier ${ }^{103,121-123}$. DEGs include classical markers CLCA1, MUC2, and TFF3, with colon GCs expressing higher mucins (MUC5B, MUC4, MUC1) and the antiprotease WFDC2 ${ }^{12}$ (Fig. 5A). Pathway enrichment analysis of DEGs confirms GCs principally act in mucus secretion, with 15 of 20 top enriched pathways involved in mucus production, including glycosylation, Golgi/ER vesicle transport, and unfolded protein response (File S3) ${ }^{124-127}$. Thus, we mapped regional GC mucin expression (Fig. 5B), finding secreted MUC2 and transmembrane MUC13 expressed across all regions and colon-enriched MUC1, MUC4, and MUC5B. While GCs are the major mucus-secreting intestinal lineage, AE 
bioRxiv preprint doi: https://doi org/10.1101/2021.10.05.460818; this version posted October 6, 2021. The copyright holder for this preprint (which was not certified by peer review) is the author/funder, who has granted bioRxiv a license to display the preprint in perpetuity. It is made available under aCC-BY-NC-ND 4.0 International license.

and ACC express transmembrane mucins that form a glycocalyx to protect against pathogenic bacteria ${ }^{128,129}$. Regional mucin expression across these lineages showed high MUC13, MUC17, and MUC3A in AEs and several enriched in ACCs (Fig. S11), informing studies regarding mucus composition and function across GCs, AEs, and ACCs.

GCs are commonly considered fairly homogenous, yet recent work in mouse colon reported transcriptional signatures of early GCs, crypt-resident (crGC), and inter-crypt goblet cells (icGC), with icGCs producing more permeable mucus than $\mathrm{crGCs}^{130}$. Human colonic secretory progenitors and GCs subclustered into similar groups marked by genes implicated in mouse GC heterogeneity: early GCs (STMN1, HMGB2, MKI67), crGCs (PDIA3, AGR2,PDIA5), and icGCs (MXD1, RAB27A, FER1L6) (Fig. 5C,F). Some canonical GC markers of mucus secretion (MUC2, ZG16) were expressed highest in icGCs, consistent with icGCs constitutively secreting mucus ${ }^{131}$. Diffusion pseudotime confirmed increasing maturity across these suppopulations (Fig. 5D-E). Notably, crGCs expressed higher MUC5B while icGCs expressed higher MUC2, MUC13, MUC1, and MUC4 (Fig. S11C), consistent with distinct mucus production in human icGCs shown via lectin staining ${ }^{130}$. Similar sub-clusters were observed in the $\mathrm{SI}$, although mucin differences were less obvious (Fig. S11D-F). This demonstrates human GCs are more heterogeneous than appreciated, necessitating studies to determine functional differences.

\section{Enteroendocrine Cells}

EECs secrete hormones to communicate between the intestine and the body. EEC hormone expression profiles are well characterized at the single-cell level in mice, since EEC reporter models enable enrichment of this rare lineage $(<1 \% \text { of intestinal epithelium })^{132,133}$. However, transcriptomic differences exist between mouse and human EECs ${ }^{132,134}$. An approach in human organoids with an EEC reporter gene yielded sufficient EECs for detailed scRNAseq analysis, though it is unclear how these cells may differ from primary human EECs ${ }^{132}$. While several human scRNAseq studies show EEC data ${ }^{11-13,16,17}$, our 154 EECs (Fig. 5G) represent the largest dataset of primary human EECs to our knowledge.

First, regional expression of hormones and other signaling machinery in EECs was surveyed. We found SCT, CHGA, TPH1, and DDC span regions with a SI bias and GCG and PYY span regions with a colonic bias (Fig. 5H). GAST and GIP express in proximal SI, while TAC1, CCK, GHRL, MLN, SST, and NTS express from duodenum through AC/TC, and INSL5 is colon-specific. Rare NPY expression was detected in jejunum and AC. These results expand on an early study using immunohistochemistry in regional biopsies to find CCK, GAST, GIP, NTS, MLN, and SCT segregated to SI regions ${ }^{135}$. Our data confirm the SI bias but show low colonic expression of $C C K, N T S, M L N$, and SCT, demonstrating the higher sensitivity in scRNAseq. NTS and $C C K$ were also absent in a study analyzing region-unspecified colon ${ }^{13}$, showing the importance of analyzing all colon regions. Fatty-acid receptors FFAR1 and FFAR2 were enriched in SI EECs and FFAR4 expression was colon-specific (Fig. 5I). The amino acid transporter SLC38A2 was well-expressed, with lower expression of other amino acid transporters. EECs also express several hormone receptors, indicating crosstalk amongst EECs. An additional form of gut-brain crosstalk was recently discovered in mice, with EECs found to form synapses with the vagus nerve ${ }^{136-138}$. DEGs from SI and colon EECs (Fig S1,S12A) are consistent with a human equivalent of these mouse EECs, termed neuropods ${ }^{137}$, with $33.7 \%$ of genes in the GOCC_Presynapse list expressed highest in EECs (Fig. S12B). Altogether, these patterns support roles for EECs in crosstalk within the gut and between the gut and brain, further illuminating their functional importance.

EECs are classified into subtypes based on hormone expression ${ }^{139,140}$. A regional breakdown of individual EECs was constructed to visualize EEC subtypes across the gut (Fig. 5J). Enterochromaffin cells (TPH1, DDC, CHGA) appear in each region with fewer in colon, and ileum unexpectedly lacks $L$ cells (GCG, $P Y Y$ ). Multiple EECs express 8-10 hormones, expanding on studies identifying poly-hormonal EECs ${ }^{141,142}$. Despite low numbers, GAST and GIP largely segregate from duodenal L cells yet overlap in jejunum. We note rare $N P Y$ expression in $M L N^{+}$and $G H R L^{+}$EECs in jejunum and AC. Future studies combining our primary EECs with additional datasets from various regions would improve our understanding of human EECs. 
bioRxiv preprint doi: https://doi.org/10.1101/2021.10.05.460818; this version posted October 6, 2021. The copyright holder for this preprint (which was not certified by peer review) is the author/funder, who has granted bioRxiv a license to display the preprint in perpetuity. It is made available under aCC-BY-NC-ND 4.0 International license.

\section{Absorptive Enterocytes and Colonocytes}

AEs and ACCs perform nearly all intestinal absorption ${ }^{143}$. These lineages formed multiple Leiden clusters, with three $A E$ clusters and two ACC clusters consistent with increasing maturity, reflecting other reports $^{11,16}$, and one cluster (AE2) separate from other AEs, largely from Donor 3 ileum (Fig. 1C,6B). A common DEG signature was defined by grouping all AEs and comparing their DEGs with all ACC DEGs. Surprisingly, only five DEGs were shared between organs (Fig. 6A), indicating stark organ differences. Interestingly, the novel AE2 population expressed mature AE markers (Fig. 6B), while uniquely expressing genes for bile acid uptake and processing ${ }^{144-146}$ (Fig. 6C). It is unclear why ileal AEs of Donor 3 clustered separately from other donors. Possible donor-specific factors contributing to this novel cluster include unique demographics (lowest BMI, African American, Type II diabetic) or differences in luminal contents between donors possibly inducing unique gene expression patterns, as described for certain genes ${ }^{92,93}$. These donorspecific differences in transcriptomic signatures highlight the need for data from wide, diverse populations.

Macro- and micro-nutrient handling was mapped across all AEs and ACCs (Fig. 6D). Nearly all fatty acid, glucose, and cholesterol transporters enriched in SI, consistent with recent work ${ }^{13}$, but regional data revealed an undescribed trend of increasing expression from duodenum through ileum for most genes (Fig. 6D). Two notable exceptions were $F A B P 1$ and $F A B P 5$, both with higher colon expression. FABP1 is expected in the proximal $\mathrm{SI}^{147}$ and $F A B P 5$ is not implicated in healthy ACCs to our knowledge, suggesting a possible role for colonic fatty acid uptake. Digestive enzymes exhibited ileal enrichment except for the duodenum-specific serine protease TMPRSS15/Enteropeptidase ${ }^{148}$. More regional variability was seen for amino acid transporters, with different genes peaking from duodenum through colon. The neutral amino acid transporter $S L C 38 A 1$ expressed in colon, in contrast to a study using colon biopsies ${ }^{149}$. Ion transporters showed the most regional differences, with SLC25A3 and SLC4A4 spanning all regions, colon-enriched SLC26A2, and SIenriched SLC9A3R1. Finally, SCNN1 sodium transporter subunits were largely enriched in colon, consistent with its need for regulated water uptake. This regional map of nutrient handling genes expands upon previous organ-level analyses, emphasizing the importance of the ileum in digestion.

Intestinal barrier function, largely conferred by cell-junction proteins, is essential for regulated absorption and physical antimicrobial defense ${ }^{150}$. The 20 highest-expressed cell junction genes were regionally evaluated (Fig. 6E). Several junction genes expressed equally across AEs and ACCs, while others exhibited regional enrichment. Claudins $(C L D N)$ are the primary determinants of tight junction barrier function and intestinal epithelial integrity ${ }^{150,151}$. CLDN1 and CLDN15 were Sl-enriched and CLDN3, CLDN4, and CLDN7 were highest in TC. Notably, no junction genes expressed highest in DC. This is intriguing, as ulcerative colitis often originates in the distal large intestine, raising the possibility that higher junction protein expression in AC and TC might protect against certain inflammatory conditions ${ }^{152-154}$. While our data cannot show pathological implications, the possibility that this differential expression pattern may protect against colitis in AC and TC is intriguing.

Aquaporins (AQPs) are the major transcellular transporters of water and small solutes in the intestine $^{155}$. Our data confirms a previous report showing elevated $A Q P 3, A Q P 7$, and $A Q P 11$ in ileum relative to colon and $A Q P 8$ elevated in colon (Fig. $6 \mathrm{~F})^{13}$, yet we find $A Q P 1$ widely expressed. Aquaglyceroporins ( $A Q P 3, A Q P 7, A Q P 10)$ increase from duodenum to ileum, coincident with increasing lipid metabolism genes (Fig. 6D). Viewing AQP across lineages (Fig. 6G) shows enriched aquaglyceroporins in mature AEs, defining a likely role for AQP-mediated glycerol transfer in AE triglyceride processing. We note unappreciated specificity of $A Q P 1$ expression in ISCs and TA cells across organs and uniquely restricted AQP8 expression in late ACCs in the AC. Diffusion pseudotime demonstrates that $A Q P 8$ is expressed in the most mature late ACCs, likely on the surface epithelium (Fig. $6 \mathrm{H}$ ). Distinct expression of $A Q P 1$ and $A Q P 8$ at the crypt base and surface, respectively, suggests specific physiological roles that should be functionally interrogated.

\section{Receptors/Drugs}

We finish by examining how extrinsic signals may affect the intestinal epithelium. Two approaches were designed to show how associations with receptors, drug targets, and lineage states can be revealed. First, expression plots were compiled of major receptor families across lineages, separated into high-, intermediate-, and low-expressing genes for easier visualization (File S5, Table S4). The five highest-expressing genes from 
each family were then grouped to visualize expression across lineages (Fig. 7A). Several patterns appear from these 60 receptors: 20 receptors are highest in tuft cells, 11 in EECs, 10 in AE/ACC, 9 in FAE; receptors bias towards villi (12) vs crypts (3); receptors bias toward SI (4) vs colon (0); and many uniquely express in certain lineages (12 in tuft, 3 in EECs, etc.), showing potential ways regions and lineages might be targeted by exogenous signals.

To test the novelty of these observations, we probed receptors with unique expression in tuft cells and searched for literature connecting these genes to tuft cells in mice or humans. We found direct connections to intestinal tuft cells for only five of the 12 (TRPM5, ITPR2, HTR3E, IL13RA1, IL17RB), with no connection to intestinal tuft cells found for the remaining seven (GABRA4, ADGRG6/GPR126, SIGIRR, ITGB5, KIT, PTPRJ, $T L R 9)$. These seven newly-defined lineage-specific receptors arose from just the five highest-expressed receptors from each family, and our full dataset includes 669 total receptors (Fig. 7B, File S5). This receptor expression atlas across lineages, organs, regions, and donors provides a powerful foundation to explore how extrinsic signals from local epithelial microenvironments, dietary and microbial influences, and pharmaceuticals affect intestinal epithelial lineages.

We explored how medicines might directly affect the intestinal epithelium. While many drugs have GIrelated side effects, few are intended to target the intestinal epithelium itself ${ }^{156-159}$, and side effects such as diarrhea are often unexplained at the cell-lineage level ${ }^{160}$. We searched for primary targets of all FDA-approved drugs and found 498 approved drugs had 232 primary gene targets expressed in our gut epithelial dataset (Fig. 7C, Table S5). As most of these drugs are prescribed for non-Gl diseases, primary targets within the intestinal epithelium are likely often overlooked and may contribute to unexpected GI side effects.

While many drugs are metabolized by the liver, oral drugs can be altered by metabolism within the gut epithelium ${ }^{157-159}$. We show expression of genes for Phase I and Phase II drug metabolism proteins by lineage with highest expression in the intestinal epithelium (Fig. 7C) and quantified gene expression by lineage and by region (Table S6). CES2, which metabolizes the cancer drug irinotecan into its biologically active form SN$38^{161}$, is found to be the highest-expressed Phase I metabolism gene in the SI, with AE enrichment. Interestingly, UGT1A1, the Phase II gene which inactivates SN-38 ${ }^{162}$, has low gut epithelial expression (Table S6). This suggests irinotecan might remain active in the gut, supporting the idea that orally administered irinotecan might be effective against intestinal cancers ${ }^{163-165}$. Our easily-searchable dataset provides expression values for genes important for further studies probing intestinal metabolism of endobiotics, environmental toxicants, and pharmaceuticals.

As an example of a disease-focused approach, we searched for primary targets of drugs prescribed for inflammatory bowel disease (IBD). Most are anti-inflammatory or immunomodulatory, so primary targets are often not expressed in the intestinal epithelium. Our database shows nine primary gene targets of eight IBD drugs with epithelial expression (Fig. 7D). As many of these drugs are intended to affect immune cells, we mapped epithelial expression of their primary target genes to see which lineages might be inadvertently affected (Fig. 7E). We find high FKBP1A, a tacrolimus (Prograf ${ }^{\circledR}$ ) target, in the little-understood BEST4 ${ }^{+}$cells, making this important to follow as their functions become better understood. Mycophenolate mofetil (CellCept ${ }^{\circledR}$ ) targets IMPDH2 and IMPDH1 expressed in proliferative crypt populations and EECs, respectively. The methotrexate target DHFR is highest in TA and progenitor cells, while the tofacitinib (Embrel $\left.{ }^{\circledR}\right)$ target JAK1 has broader expression. These drugs can be orally administered and have side effects including diarrhea, nausea, vomiting, or appetite loss ${ }^{166-168}$. Interrogating this small subset of drugs in our database highlights a spectrum of potential unintended epithelial effects on renewal by ISC or TA cells, EEC hormonal influences on appetite and gut motility, and unknown effects from other lineages.

Personalized precision medicine is an emerging field motivating new technologies ${ }^{169}$. We used our drug-target atlas to evaluate regional variability of tacrolimus, mycophenolate mofetil, and tofacitinib target genes, FKBP1A, IMPDH2, and JAK1, across individual donors as an approach to inform potential patientdependent effects (Fig. 7F). We find higher colonic expression of all three targets, suggesting that patients may experience effects of drugs targeting these genes in their lower GI tract. Comparing multiple donors may hint at susceptibility to drug side-effects, with Donors 2 and 3 generally expressing target genes higher than Donor 1 . 
While our donor number is insufficient for statistically significant conclusions, it provides a framework to generate observations to inform larger studies. We hope our lineage-, regional-, and donor-specific data on primary drug targets will be used across gastroenterology and pharmacology to better understand how drugs may affect the intestinal epithelium.

\section{Discussion}

We use transplant organ tissue to characterize intestinal epithelial cells from duodenum through DC for three adult human donors, allowing us to define comprehensive lineage markers and map regional functionality. Our experimental design has many strengths not found in other studies. DNA-oligo hashtag antibodies allowed for all six regions from each donor to be sequenced together to save cost and avoid intradonor batch effects, then separated computationally to analyze regional differences. This allowed for comparing gene expression between multiple regions within SI or colon. The regional differences found highlight the importance of regional selection when studying the gut, yet many colonic scRNAseq studies do not specify sample region or mention if pooled samples are from consistent regions. We analyzed cells from donors with no known intestinal diseases or cancer, avoiding effects on non-inflamed adjacent tissues in patients with inflammatory disease ${ }^{9}$.

Our experimental design allowed us to study many specific phenomena. Analyzing cells across six regions allowed us to compile comprehensive transcriptional signatures of genes significantly enriched in each lineage versus other lineages in all six regions and across donors. We map mucins, hormones, transporters, and barrier function genes across all six regions. We analyze PCs, showing drastic differences in growth factor expression from mouse literature and highlighting the insufficiency of $L Y Z$ for marking human PCs. We also analyze rare FAE cells, showing mouse/human differences and defining DEGs. We use PAGA to infer the differentiation trajectory for each lineage and suggest organ-specific maturation for tuft and BEST4 $4^{+}$cells. We propose novel tuft cell interactions with pathogens and the immune system. Finally, we map receptor expression and primary drug targets across lineages and highlight the ease of using this database to find previously undescribed gene expression. We hope our database serves as a resource to understand how drugs affect the intestinal epithelium and as guidance for future precision medicine approaches.

SI and colon from three male donors varying in age, race, and BMI were used in our study. Optimally, future studies will add regional data from diverse donors to build upon this foundation. While multiplexing six regions in one library prep allowed us to make a wide-ranging atlas, this approach results in limited numbers of each lineage analyzed per region. Our trajectory analysis suggests which lineages mature through secretory progenitors, yet future studies including more progenitors may provide more sensitive and high-resolution analyses.

In this study, we provide a comprehensive cell-level transcriptomic view of the SI and colon epithelium with regional resolution across multiple humans. Our analyses independently confirm and advance prior studies, define important differences between mouse and human lineages, and highlight how lineages change along the proximal-distal axis. We include easy-to-search tables for DEGs, receptors, and drug targets that can be interrogated by most investigators and trainees. Overall, our database provides a foundation for understanding individual contributions of diverse epithelial cells across the length of the human intestine and colon to maintaining physiologic function.

\section{Figure Legends}

Figure 1: Sample Processing. A) Schematic for isolating cells from six intestinal regions for three donors and using hashtag antibodies to sequence regions side-by-side. B) UMAP of analyzed cells in 25 lineage clusters. C-E) UMAP of all cells by donor (C) or region (D,E). F-G) Heatmaps showing unique markers for major lineages in SI (F) and colon (G).

Figure 2: Proliferative crypt populations. A) Heatmap of DEGs in ISCs vs. other lineages (top; red: classical markers), SI vs. colon ISCs (middle), colon vs. SI ISCs (bottom). B) UMAP of LGR5, OLFM4, and RARRES2 expression. C) Venn Diagram showing overlap between murine and human ISC signatures. D) Heatmap of 
DEGs in TA cells vs. other lineages (top), SI vs. colon TA cells (middle), colon vs. SI TA cells (bottom). E) Dotplot showing DEGs from SI or colon-specific lineages within organ-delineated ISCs and TA cells. F,G) Partition-based graph abstraction (PAGA) showing connectivity between major lineages in SI (F) and colon (G) to infer maturation trajectory. Line thickness represents connectivity strength. H-J) Regional cell cycle phase distribution in ISCs $(\mathrm{H})$, TA cells (I), and secretory progenitors (J).

Figure 3: Paneth and BEST4 ${ }^{+}$cells. A) Heatmap of DEGs in PCs vs. other lineages (red: classical markers). B) Dotplot showing Lysozyme across FAE, BEST4, Paneth, and tuft cells. C) Dotplot showing PC, goblet, and BEST4 markers. D) Dotplot showing growth factors implicated in murine PCs across SI lineages. E) Heatmap showing PC and ISC markers across both lineages. F) Dotplot showing 10 highest-expressed antimicrobial peptides across SI lineages. G) Heatmap of DEGs in BEST4 ${ }^{+}$cells vs other lineages (top; red: classical markers), SI vs. colon BEST4 ${ }^{+}$cells (middle), colon vs. SI BEST4 ${ }^{+}$cells (bottom). H) Dotplot showing secreted genes and their receptors across lineages. I) UMAPs of BEST4 ${ }^{+}$cells showing predicted diffusion pseudotime and expression of secreted peptides. J) Expression of $N P Y, S I$, and APOA1 across regions by donor. K) Dotplot showing genes involved in metal-binding and endocytosis across lineages.

Figure 4: Tuft Cells. A) Heatmap of DEGs in tuft cells vs. other lineages (top; red: classical markers), SI vs. colon tuft cells (middle), colon vs. SI tuft cells (bottom). B) Dotplot showing tuft cell enrichment of genes specific to taste signal transduction. C) Organ-specific signal transduction in SI vs. colon tuft cells. D) Dotplot showing tuft cell-enriched genes enabling interactions with innate and adaptive immune system. E) Dotplot showing 10 highest-expressed antimicrobial peptides across colon lineages. F) Dotplot showing tuft cellspecific genes for producing acetylcholine, eicosanoids, and prostaglandins.

Figure 5: Goblet and Enteroendocrine Cells. A) Heatmap of DEGs in GCs vs. other lineages (top; red: classical markers), SI vs. colon GCs (middle), colon vs. SI GCs (bottom). B) Dotplot showing 9 highestexpressed mucins across GCs by region (blue: gel-forming mucins). C) Leiden sub-clustering of colon GCs. D) Diffusion pseudotime of colon GCs. E) UMAP of MUC2 expression in colon GCs. F) Dotplot showing mouseimplicated markers in human colon GC subclusters. G) Heatmap of DEGs in EECs vs. other lineages (top, red: classical markers), SI vs. colon EECs (middle), colon vs. SI EECs (bottom). H) Dotplot of EEC regional hormone gene expression. I) Dotplot of EEC expression of select receptors by region. J) Heatmap showing hormone expression in each EEC.

Figure 6: Absorptive cells. A) Heatmap of DEGs in absorptive cells vs. other lineages (top) AEs vs. ACCs (middle), ACCs vs. SI AEs (bottom). B) UMAPs showing AE2 Leiden cluster (top) and cells by region (bottom). C) Dotplot of classical Mature AE markers and top 10 DEGs for AE2 cluster. D) Dotplots showing regional expression of genes involved in digestion and absorption in all AEs and ACCs. E) Dotplots showing 20 highestexpressed cell junction genes in AEs and ACCs by region. F) Dotplots showing regional aquaporin expression in AEs and ACCs. G) Aquaporin expression across lineages. H) UMAPs of late ACCs showing predicted diffusion pseudotime (left) and AQP8 expression (right).

Figure 7: Extrinsic receptors and drug targets. A) Dotplot showing five highest-expressing members of major receptor families by lineage. B) Pie chart showing receptor genes expressed in the intestinal epithelium by lineage with highest expression. C) Pie chart showing primary targets of all approved drugs and Phase I and Phase II drug metabolism genes expressed in the intestinal epithelium by lineage with highest expression. D-E) Primary targets of drugs used to treat IBD by expression across lineages. Note scaling changes. F) Dotplot showing expression of three targets of IBD drugs across regions split by donor.

\section{Supplemental Figures and Files}

Figure S1: Patient characteristics and cell counts. A) Donor information. B) Cells collected per donor region. C) Small intestinal lineages collected per donor. D) Colonic lineages collected per donor. E) Small intestinal lineages per donor region. F) Colonic lineages per donor region.

Figure S2: Tissue histology. Hemotoxylin and eosin stained tissues from each region for all three donors. All scale bars $=200 \mu \mathrm{m}$ 
Figure S3: FACS strategy. FACS strategy for gating out cell fragments, likely doublets, and dead cells. 'APC$A^{\prime}$ channel is detecting AnnexinV-APC.

Figure S4: Hashtag deconvolution. A) Per donor hashtag noise distributions. Blue dotted lines indicate $99^{\text {th }}$ percentile values for noise. Values above this line were called positive for a specific hashtag. B) (left) Kmedoid clustering for each donor based only on hashtag reads. Cells positive $(p<0.01)$ for mulitple hashtags are removed as likely multiplets. Cells are called as negative if they do not surpass the noise threshold for all hashtags, (right) k-medoid clustering with final hasthag labelling for non-multiplet cells

Figure S5: Filtering for cell quality. Total counts, $\mathrm{N}$ genes, and mitochondrial gene percentages shown for each donor before and after filtering; (top) pre-filtering and (bottom) post filtering.

Figure S6: Determining final lineage clusters. A) Original Leiden clustering for all cells. B) Seperating EEC and secretory progenitors by organ. C-E) An ITLN1-high cluster, all from SI, contains cells expressing PC markers (DEFA5, DEFA6, ITLN2, LYZ) along with cells expressing GC marker MUC2. (C) cluster defined by ITLN1 and dotplot showing expression of markes; (D) UMAP expression of PC and GC markers across all cells; (E) UMAP expression of PC and GC markers within the ITLN1-high cluster. F) Subclustering to define Paneth and goblet cells. G) Final lineage clusters used for the rest of the analyses in our study.

Figure S7: DEG dotplots for each lineage. Dotplots showing expression of top DEGs (max: 20) for each lineage, as sorted by expression fold-change above the cluster with the next highest expression. DEGs included are genes significantly enriched in both the SI and colon (if applicable).

Figure S8: Organ-specific lineage markers. Relating to Fig. 2E, UMAPs showing expression of DEGs from mature lineages found to be higher enriched in SI or colon.

Figure S9: Additional Paneth cell data. A) Dotplot showing members of major intestinal growth factor families with expression in PCs across SI lineages. B) Dotplot showing expression of all Frizzled family receptors across SI lineages. C) Heatmap of GC markers (top), mouse-defined Paneth-Like Cell markers (middle), and PC markers (bottom) plotted across colon GCs, secretroy progenitors, and tuft cells. Cells in each lineage are sorted by increasing REG4 expression (top row of middle third) to more easily visualize potenital overlap of marker expression.

Figure S10: Follicle Associated Epithelium. A) Dotplot showing expression of consrved M-cell markers and other genes known to interact with the immune system across lineages. Bottom third shows genes implicated in mouse M-cells that are not specific to human FAE. B) Dotplot showing expression of top 20 FAE DEGs across lineages.

Figure S11: Additional mucin and goblet cell data. A) Dotplot showing expression of top nine expressing mucins across GCs and proliferative and absorptive lineages of the SI and colon. B) Dotplot showing expression of top 9 expressed mucins in all AE and ACC lineages by intestinal region. C) Dotplot showing expression of mucins in colonic intercrypt goblet cells (icGC), crypt-resident goblet cells (crGCs), and early goblet cells. D) (Left) Leiden subclustering of SI goblet cells, with subclusters named according to genes with high expression. (Middle) UMAP of SI goblet cells marked by diffusion pseudotime. (Right) UMAP of SI goblet cells marked by MUC2 expression. E) Dotplot showing expression of mucins in SI GC subpopulations. F) Dotplot showing expression of mouse-implicated markers in human SI GC subclusters.

Figure S12: Additional EEC Data. A) Dotplot showing expression of DEGs found for SI or colon EECs that are present in the GOCC_Presynapse gene list. B) Pie chart showing all genes within the GOCC_Presynapse gene list marked by lineage in which they have highest expression ( $\mathrm{SI}$ and colon lineages are combined when applicable).

File S1: REACTOME pathway enrichment analysis for TA vs TA2

File S2: REACTOME pathway enrichment analysis for TA2 vs TA

File S3: REACTOME pathway enrichment analysis for FAE DEGs 


\section{File S4: REACTOME pathway enrichment analysis for goblet cell DEGs}

\section{File S5: Receptor Family dotplots by lineage}

\section{Table S1: Differentially expressed gene signatures for lineages by organ}

\section{Table S2: Lineage signatures across full gut}

\section{Table S3: Correlations for BEST4+ NPY and AE gene expression}

\section{Table S4: Receptor family expression by lineage}

\section{Table S5: Primary targets of approved drugs expressed by lineage}

\section{Table S6: Phase I and Phase II drug metabolism genes expressed by lineage}

\section{Acknowledgements}

We first thank the organ donors without whom our study would be impossible. We thank HonorBridge (formerly Carolina Donor Services) for assistance in coordinating organ donations. We thank Gabrielle Cannon at the Advanced Analytics core at UNC Chapel Hill and the Histology Research Core at UNC Chapel Hill. This work was supported by NIH R01DK115806, R01DK109559, and P30-DK034987 to STM, F32DK124929 to JRB, and F31-HL156433 and 5T32-GM067553 for JSR. APB is supported by a Career Development Award from the Crohn's and Colitis Foundation, and the University Cancer Research Fund.

\section{Works cited}

1. Barker N. Adult intestinal stem cells: critical drivers of epithelial homeostasis and regeneration. Nat Rev Mol Cell Biol 2014;15:19-33.

2. Mowat AM, Agace WW. Regional specialization within the intestinal immune system. Nat Rev Immunol 2014;14:667-85.

3. Grün D, Lyubimova A, Kester L, et al. Single-cell messenger RNA sequencing reveals rare intestinal cell types. Nature 2015;525:251-255.

4. Kim TH, Saadatpour A, Guo G, et al. Single-Cell Transcript Profiles Reveal Multilineage Priming in Early Progenitors Derived from Lgr5+ Intestinal Stem Cells. Cell Reports 2016;16:2053-2060.

5. Haber AL, Biton M, Rogel N, et al. A single-cell survey of the small intestinal epithelium. Nature 2017;551:333339.

6. Holloway EM, Czerwinski M, Tsai YH, et al. Mapping Development of the Human Intestinal Niche at Single-Cell Resolution. Cell Stem Cell 2020;28:568-580.e4.

7. Fawkner-Corbett D, Antanaviciute A, Parikh K, et al. Spatiotemporal analysis of human intestinal development at single-cell resolution. Cell 2021;184:810-826.e23.

8. Elmentaite R, Ross ADB, Roberts K, et al. Single-Cell Sequencing of Developing Human Gut Reveals Transcriptional Links to Childhood Crohn's Disease. Dev Cell 2020;55:771-783 e5.

9. Smillie CS, Biton M, Ordovas-Montanes J, et al. Intra- and Inter-cellular Rewiring of the Human Colon during Ulcerative Colitis. Cell 2019;178:714-730.e22.

10. Huang B, Chen Z, Geng L, et al. Mucosal Profiling of Pediatric-Onset Colitis and IBD Reveals Common Pathogenics and Therapeutic Pathways. Cell 2019;179:1160-1176.e24.

11. Kanke M, Kennedy MM, Connelly $S$, et al. Single-cell analysis of colonic epithelium reveals unexpected shifts in cellular composition and molecular phenotype in treatment-naïve adult Crohn's disease. bioRxiv 2021:2021.01.13.426602.

12. Parikh K, Antanaviciute A, Fawkner-Corbett D, et al. Colonic epithelial cell diversity in health and inflammatory bowel disease. Nature 2019;567:49-55.

13. Wang $\mathrm{Y}$, Song W, Wang J, et al. Single-cell transcriptome analysis reveals differential nutrient absorption functions in human intestine. J Exp Med 2020;217.

14. Fujii M, Matano M, Toshimitsu K, et al. Human Intestinal Organoids Maintain Self-Renewal Capacity and Cellular Diversity in Niche-Inspired Culture Condition. Cell Stem Cell 2018;23:787-793.e6. 
bioRxiv preprint doi: https://doi.org/10.1101/2021.10.05.460818; this version posted October 6, 2021. The copyright holder for this preprint (which was not certified by peer review) is the author/funder, who has granted bioRxiv a license to display the preprint in perpetuity. It is made available under aCC-BY-NC-ND 4.0 International license.

15. Triana S, Stanifer ML, Metz-Zumaran C, et al. Single-cell transcriptomics reveals immune response of intestinal cell types to viral infection. Mol Syst Biol 2021;17:e9833.

16. Busslinger GA, Weusten BLA, Bogte A, et al. Human gastrointestinal epithelia of the esophagus, stomach, and duodenum resolved at single-cell resolution. Cell Reports 2021;34:108819.

17. Elmentaite R, Kumasaka N, Roberts K, et al. Cells of the human intestinal tract mapped across space and time. Nature 2021;597:250-255.

18. Wang Y, Gunasekara DB, Reed MI, et al. A microengineered collagen scaffold for generating a polarized cryptvillus architecture of human small intestinal epithelium. Biomaterials 2017;128:44-55.

19. Stoeckius M, Zheng S, Houck-Loomis B, et al. Cell Hashing with barcoded antibodies enables multiplexing and doublet detection for single cell genomics. Genome Biol 2018;19:224.

20. Korsunsky I, Millard N, Fan J, et al. Fast, sensitive and accurate integration of single-cell data with Harmony. Nat Methods 2019;16:1289-1296.

21. Traag VA, Waltman L, van Eck NJ. From Louvain to Leiden: guaranteeing well-connected communities. Sci Rep 2019;9:5233.

22. Wolf FA, Hamey FK, Plass M, et al. PAGA: graph abstraction reconciles clustering with trajectory inference through a topology preserving map of single cells. Genome Biol 2019;20:59.

23. Barker N, van Es JH, Kuipers J, et al. Identification of stem cells in small intestine and colon by marker gene Lgr5. Nature 2007;449:1003-7.

24. van der Flier LG, van Gijn ME, Hatzis $P$, et al. Transcription factor achaete scute-like 2 controls intestinal stem cell fate. Cell 2009;136:903-12.

25. Whissell G, Montagni E, Martinelli P, et al. The transcription factor GATA6 enables self-renewal of colon adenoma stem cells by repressing BMP gene expression. Nat Cell Biol 2014;16:695-707.

26. Munoz J, Stange DE, Schepers AG, et al. The Lgr5 intestinal stem cell signature: robust expression of proposed quiescent ' +4 ' cell markers. EMBO J 2012;31:3079-91.

27. van der Flier LG, Haegebarth A, Stange DE, et al. OLFM4 is a robust marker for stem cells in human intestine and marks a subset of colorectal cancer cells. Gastroenterology 2009;137:15-7.

28. Habowski AN, Flesher JL, Bates JM, et al. Transcriptomic and proteomic signatures of stemness and differentiation in the colon crypt. Commun Biol 2020;3:453.

29. Merlos-Suarez A, Barriga FM, Jung $P$, et al. The intestinal stem cell signature identifies colorectal cancer stem cells and predicts disease relapse. Cell Stem Cell 2011;8:511-24.

30. Gabut M, Bourdelais F, Durand S. Ribosome and Translational Control in Stem Cells. Cells 2020;9.

31. Woolnough JL, Atwood BL, Liu Z, et al. The Regulation of rRNA Gene Transcription during Directed Differentiation of Human Embryonic Stem Cells. PLoS One 2016;11:e0157276.

32. Zhang Q, Shalaby NA, Buszczak M. Changes in rRNA transcription influence proliferation and cell fate within a stem cell lineage. Science 2014;343:298-301.

33. Marshman E, Booth C, Potten CS. The intestinal epithelial stem cell. Bioessays 2002;24:91-8.

34. Kristensen AR, Gsponer J, Foster L. Protein synthesis rate is the predominant regulator of protein expression during differentiation. Mol Syst Biol 2013;9:689.

35. Fu W, Liu Y, Yin H. Mitochondrial Dynamics: Biogenesis, Fission, Fusion, and Mitophagy in the Regulation of Stem Cell Behaviors. Stem Cells Int 2019;2019:9757201.

36. Lu R, Markowetz F, Unwin RD, et al. Systems-level dynamic analyses of fate change in murine embryonic stem cells. Nature 2009;462:358-62.

37. Avansino JR, Chen DC, Hoagland VD, et al. Orthotopic transplantation of intestinal mucosal organoids in rodents. Surgery 2006;140:423-34.

38. Fukuda M, Mizutani T, Mochizuki W, et al. Small intestinal stem cell identity is maintained with functional Paneth cells in heterotopically grafted epithelium onto the colon. Genes Dev 2014;28:1752-7.

39. Herring CA, Banerjee A, McKinley ET, et al. Unsupervised Trajectory Analysis of Single-Cell RNA-Seq and Imaging Data Reveals Alternative Tuft Cell Origins in the Gut. Cell Syst 2018;6:37-51 e9.

40. van Es JH, Sato $T$, van de Wetering $M$, et al. Dll1+ secretory progenitor cells revert to stem cells upon crypt damage. Nat Cell Biol 2012;14:1099-1104.

41. Yang Q, Bermingham NA, Finegold MJ, et al. Requirement of Math1 for secretory cell lineage commitment in the mouse intestine. Science 2001;294:2155-8. 
bioRxiv preprint doi: https://doi.org/10.1101/2021.10.05.460818; this version posted October 6, 2021. The copyright holder for this preprint (which was not certified by peer review) is the author/funder, who has granted bioRxiv a license to display the preprint in perpetuity. It is made available under aCC-BY-NC-ND 4.0 International license.

42. Sancho R, Cremona CA, Behrens A. Stem cell and progenitor fate in the mammalian intestine: Notch and lateral inhibition in homeostasis and disease. EMBO Rep 2015;16:571-81.

43. Kowalczyk MS, Tirosh I, Heckl D, et al. Single-cell RNA-seq reveals changes in cell cycle and differentiation programs upon aging of hematopoietic stem cells. Genome Res 2015;25:1860-72.

44. Wang $\mathrm{Y}$, Song $\mathrm{W}$, Wang J, et al. Single-cell transcriptome analysis reveals differential nutrient absorption functions in human intestine. Journal of Experimental Medicine 2020;217.

45. Wille AC, Oliveira FA, Soares MA, et al. Cell cycle time and rate of entry of cells into mitosis in the small intestine of young rats. Cell Prolif 2004;37:189-94.

46. Gandara RM, Mahida YR, Potten CS. Regional differences in stem and transit cell proliferation and apoptosis in the terminal ileum and colon of mice after 12 Gy. Int J Radiat Oncol Biol Phys 2012;82:e521-8.

47. Dalton S. Linking the Cell Cycle to Cell Fate Decisions. Trends Cell Biol 2015;25:592-600.

48. Sato T, van Es JH, Snippert HJ, et al. Paneth cells constitute the niche for Lgr5 stem cells in intestinal crypts. Nature 2011;469:415-8.

49. Poulsen SS, Nexo E, Olsen PS, et al. Immunohistochemical localization of epidermal growth factor in rat and man. Histochemistry 1986;85:389-94.

50. Zhao J, de Vera J, Narushima S, et al. R-spondin1, a novel intestinotrophic mitogen, ameliorates experimental colitis in mice. Gastroenterology 2007;132:1331-43.

51. Shoshkes-Carmel M, Wang YJ, Wangensteen KJ, et al. Subepithelial telocytes are an important source of Wnts that supports intestinal crypts. Nature 2018;557:242-246.

52. Degirmenci B, Valenta T, Dimitrieva S, et al. GLI1-expressing mesenchymal cells form the essential Wnt-secreting niche for colon stem cells. Nature 2018;558:449-453.

53. Kabiri Z, Greicius G, Madan B, et al. Stroma provides an intestinal stem cell niche in the absence of epithelial Wnts. Development 2014;141:2206-15.

54. Durand A, Donahue B, Peignon G, et al. Functional intestinal stem cells after Paneth cell ablation induced by the loss of transcription factor Math1 (Atoh1). Proc Natl Acad Sci U S A 2012;109:8965-70.

55. Kim TH, Escudero S, Shivdasani RA. Intact function of Lgr5 receptor-expressing intestinal stem cells in the absence of Paneth cells. Proc Natl Acad Sci U S A 2012;109:3932-7.

56. Farin HF, Van Es JH, Clevers H. Redundant sources of Wnt regulate intestinal stem cells and promote formation of Paneth cells. Gastroenterology 2012;143:1518-1529 e7.

57. Lu H, Ju DD, Yang GD, et al. Targeting cancer stem cell signature gene SMOC-2 Overcomes chemoresistance and inhibits cell proliferation of endometrial carcinoma. EBioMedicine 2019;40:276-289.

58. Jubb AM, Chalasani S, Frantz GD, et al. Achaete-scute like 2 (ascl2) is a target of Wnt signalling and is upregulated in intestinal neoplasia. Oncogene 2006;25:3445-57.

59. Schuijers J, Junker JP, Mokry M, et al. Ascl2 acts as an R-spondin/Wnt-responsive switch to control stemness in intestinal crypts. Cell Stem Cell 2015;16:158-70.

60. Flanagan DJ, Phesse TJ, Barker N, et al. Frizzled7 functions as a Wnt receptor in intestinal epithelial Lgr5(+) stem cells. Stem Cell Reports 2015;4:759-67.

61. Karasawa T, Yokokura H, Kitajewski J, et al. Frizzled-9 is activated by Wnt-2 and functions in Wnt/beta -catenin signaling. J Biol Chem 2002;277:37479-86.

62. Liu X, Lu R, Wu S, et al. Wnt2 inhibits enteric bacterial-induced inflammation in intestinal epithelial cells. Inflamm Bowel Dis 2012;18:418-29.

63. Kramer N, Schmollerl J, Unger C, et al. Autocrine WNT2 signaling in fibroblasts promotes colorectal cancer progression. Oncogene 2017;36:5460-5472.

64. Huang TX, Tan XY, Huang HS, et al. Targeting cancer-associated fibroblast-secreted WNT2 restores dendritic cellmediated antitumour immunity. Gut 2021.

65. Jones JC, Brindley CD, Elder NH, et al. Cellular Plasticity of Defa4-Expressing Paneth Cells in Response to Notch Activation and Intestinal Injury. Cellular and Molecular Gastroenterology and Hepatology 2018:1-21.

66. Schmitt M, Schewe M, Sacchetti A, et al. Paneth Cells Respond to Inflammation and Contribute to Tissue Regeneration by Acquiring Stem-like Features through SCF/c-Kit Signaling. Cell Reports 2018;24:2312-2328.e7.

67. Yu S, Tong K, Zhao Y, et al. Paneth Cell Multipotency Induced by Notch Activation following Injury. Cell Stem Cell 2018:1-14.

68. Murata K, Jadhav U, Madha S, et al. Ascl2-Dependent Cell Dedifferentiation Drives Regeneration of Ablated Intestinal Stem Cells. Cell Stem Cell 2020;26:377-390 e6. 
bioRxiv preprint doi: https://doi.org/10.1101/2021.10.05.460818; this version posted October 6, 2021. The copyright holder for this preprint (which was not certified by peer review) is the author/funder, who has granted bioRxiv a license to display the preprint in perpetuity. It is made available under aCC-BY-NC-ND 4.0 International license.

69. Rothenberg ME, Nusse $\mathrm{Y}$, Kalisky $\mathrm{T}$, et al. Identification of a cKit+ colonic crypt base secretory cell that supports Lgr5+ stem cells in mice. Gastroenterology 2012;142:1195-1205.e6.

70. Sasaki N, Sachs N, Wiebrands K, et al. Reg4+ deep crypt secretory cells function as epithelial niche for Lgr5+ stem cells in colon. Proceedings of the National Academy of Sciences of the United States of America 2016;113:E5399E5407.

71. Salzman NH. Paneth cell defensins and the regulation of the microbiome: detente at mucosal surfaces. Gut Microbes 2010;1:401-6.

72. Jorgensen PB, Fenton TM, Morbe UM, et al. Identification, isolation and analysis of human gut-associated lymphoid tissues. Nat Protoc 2021;16:2051-2067.

73. Dillon A, Lo DD. M Cells: Intelligent Engineering of Mucosal Immune Surveillance. Front Immunol 2019;10:1499.

74. Hase K, Ohshima S, Kawano K, et al. Distinct gene expression profiles characterize cellular phenotypes of follicleassociated epithelium and $M$ cells. DNA Res 2005;12:127-37.

75. Terahara K, Yoshida M, Igarashi $\mathrm{O}$, et al. Comprehensive gene expression profiling of Peyer's patch $\mathrm{M}$ cells, villous M-like cells, and intestinal epithelial cells. J Immunol 2008;180:7840-6.

76. Nakato G, Fukuda S, Hase K, et al. New approach for m-cell-specific molecules screening by comprehensive transcriptome analysis. DNA Res 2009;16:227-35.

77. Lo D, Tynan W, Dickerson J, et al. Cell culture modeling of specialized tissue: identification of genes expressed specifically by follicle-associated epithelium of Peyer's patch by expression profiling of Caco-2/Raji co-cultures. Int Immunol 2004;16:91-9.

78. Kimura S, Kobayashi N, Nakamura $\mathrm{Y}$, et al. Sox8 is essential for $\mathrm{M}$ cell maturation to accelerate IgA response at the early stage after weaning in mice. J Exp Med 2019;216:831-846.

79. Nakamura Y, Kimura S, Hase K. M cell-dependent antigen uptake on follicle-associated epithelium for mucosal immune surveillance. Inflamm Regen 2018;38:15.

80. Mercado-Lubo R, McCormick BA. A unique subset of Peyer's patches express lysozyme. Gastroenterology 2010;138:36-9.

81. Hase K, Murakami T, Takatsu H, et al. The membrane-bound chemokine CXCL16 expressed on follicle-associated epithelium and $M$ cells mediates lympho-epithelial interaction in GALT. J Immunol 2006;176:43-51.

82. Zhao X, Sato A, Dela Cruz CS, et al. CCL9 is secreted by the follicle-associated epithelium and recruits dome region Peyer's patch CD11b+ dendritic cells. J Immunol 2003;171:2797-803.

83. Begg DP, Steinbrecher KA, Mul JD, et al. Effect of guanylate cyclase-C activity on energy and glucose homeostasis. Diabetes 2014;63:3798-804.

84. Sindic A. Current understanding of guanylin peptides actions. ISRN Nephrol 2013;2013:813648.

85. Valentino MA, Lin JE, Snook AE, et al. A uroguanylin-GUCY2C endocrine axis regulates feeding in mice. J Clin Invest 2011;121:3578-88.

86. Cox HM. Neuropeptide Y receptors; antisecretory control of intestinal epithelial function. Auton Neurosci 2007;133:76-85.

87. Wen J, Liu X, Qi Y, et al. BMP3 suppresses colon tumorigenesis via ActRIIB/SMAD2-dependent and TAK1/JNK signaling pathways. J Exp Clin Cancer Res 2019;38:428.

88. Loh K, Chia JA, Greco S, et al. Bone morphogenic protein 3 inactivation is an early and frequent event in colorectal cancer development. Genes Chromosomes Cancer 2008;47:449-60.

89. Haghverdi L, Buttner M, Wolf FA, et al. Diffusion pseudotime robustly reconstructs lineage branching. Nat Methods 2016;13:845-8.

90. Holzer P, Reichmann F, Farzi A. Neuropeptide $Y$, peptide $Y Y$ and pancreatic polypeptide in the gut-brain axis. Neuropeptides 2012;46:261-74.

91. Loh K, Herzog H, Shi YC. Regulation of energy homeostasis by the NPY system. Trends Endocrinol Metab 2015;26:125-35.

92. Kishi K, Takase S, Goda T. Enhancement of sucrase-isomaltase gene expression induced by luminally administered fructose in rat jejunum. J Nutr Biochem 1999;10:8-12.

93. Kalogeris TJ, Rodriguez MD, Tso P. Control of synthesis and secretion of intestinal apolipoprotein A-IV by lipid. J Nutr 1997;127:537S-543S.

94. Scheibner J, Trendelenburg AU, Hein L, et al. Alpha 2-adrenoceptors in the enteric nervous system: a study in alpha 2A-adrenoceptor-deficient mice. Br J Pharmacol 2002;135:697-704.

95. Si M, Lang J. The roles of metallothioneins in carcinogenesis. J Hematol Oncol 2018;11:107. 
bioRxiv preprint doi: https://doi.org/10.1101/2021.10.05.460818; this version posted October 6, 2021. The copyright holder for this preprint (which was not certified by peer review) is the author/funder, who has granted bioRxiv a license to display the preprint in perpetuity. It is made available under aCC-BY-NC-ND 4.0 International license.

96. Klaassen CD, Liu J, Diwan BA. Metallothionein protection of cadmium toxicity. Toxicol Appl Pharmacol 2009;238:215-20.

97. Coyle P, Philcox JC, Carey LC, et al. Metallothionein: the multipurpose protein. Cell Mol Life Sci 2002;59:627-47.

98. Ohgami RS, Campagna DR, McDonald A, et al. The Steap proteins are metalloreductases. Blood 2006;108:138894.

99. Anderson GJ, Frazer DM. Current understanding of iron homeostasis. Am J Clin Nutr 2017;106:1559S-1566S.

100. Schneider C, O'Leary CE, Locksley RM. Regulation of immune responses by tuft cells. Nature Reviews. Immunology 2019;19:584-593.

101. O'Leary CE, Schneider C, Locksley RM. Tuft Cells-Systemically Dispersed Sensory Epithelia Integrating Immune and Neural Circuitry. Annual Review of Immunology 2019;37:47-72.

102. Nadjsombati MS, McGinty JW, Lyons-Cohen MR, et al. Detection of Succinate by Intestinal Tuft Cells Triggers a Type 2 Innate Immune Circuit. Immunity 2018;49:33-41 e7.

103. von Moltke J, Ji M, Liang HE, et al. Tuft-cell-derived IL-25 regulates an intestinal ILC2-epithelial response circuit. Nature 2016;529:221-5.

104. Howitt MR, Lavoie S, Michaud M, et al. Tuft cells, taste-chemosensory cells, orchestrate parasite type 2 immunity in the gut. Science 2016;351:1329-33.

105. Gerbe F, van Es JH, Makrini L, et al. Distinct ATOH1 and Neurog3 requirements define tuft cells as a new secretory cell type in the intestinal epithelium. J Cell Biol 2011;192:767-80.

106. Bezençon C, Fürholz A, Raymond F, et al. Murine intestinal cells expressing Trpm5 are mostly brush cells and express markers of neuronal and inflammatory cells. The Journal of Comparative Neurology 2008;509:514-525.

107. Schneider C, O'Leary CE, von Moltke J, et al. A Metabolite-Triggered Tuft Cell-ILC2 Circuit Drives Small Intestinal Remodeling. Cell 2018;174:271-284 e14.

108. Roper SD, Chaudhari N. Taste buds: cells, signals and synapses. Nature Reviews. Neuroscience 2017;18:485-497.

109. Kinnamon SC. Taste receptor signalling - from tongues to lungs. Acta Physiol (Oxf) 2012;204:158-68.

110. Vyas JM, Van der Veen AG, Ploegh HL. The known unknowns of antigen processing and presentation. Nat Rev Immunol 2008;8:607-18.

111. Kloetzel PM, Ossendorp F. Proteasome and peptidase function in MHC-class-I-mediated antigen presentation. Curr Opin Immunol 2004;16:76-81.

112. Lu Y-C, Yeh W-C, Ohashi PS. LPS/TLR4 signal transduction pathway. Cytokine 2008;42:145-151.

113. Hayashi F, Smith KD, Ozinsky A, et al. The innate immune response to bacterial flagellin is mediated by Toll-like receptor 5. Nature 2001;410:1099-1103.

114. Bauer S, Kirschning $\mathrm{CJ}$, Häcker $\mathrm{H}$, et al. Human TLR9 confers responsiveness to bacterial DNA via species-specific CpG motif recognition. Proceedings of the National Academy of Sciences of the United States of America 2001;98:9237-9242.

115. Xu M, Lu H, Lee YH, et al. An Interleukin-25-Mediated Autoregulatory Circuit in Keratinocytes Plays a Pivotal Role in Psoriatic Skin Inflammation. Immunity 2018;48:787-798 e4.

116. Wald D, Qin J, Zhao Z, et al. SIGIRR, a negative regulator of Toll-like receptor-interleukin 1 receptor signaling. Nat Immunol 2003;4:920-7.

117. Zhang C, Wu X, Zhao Y, et al. SIGIRR inhibits toll-like receptor 4, 5, 9-mediated immune responses in human airway epithelial cells. Mol Biol Rep 2011;38:601-9.

118. Qin J, Qian Y, Yao J, et al. SIGIRR inhibits interleukin-1 receptor- and toll-like receptor 4-mediated signaling through different mechanisms. J Biol Chem 2005;280:25233-41.

119. Schütz B, Ruppert A-L, Strobel O, et al. Distribution pattern and molecular signature of cholinergic tuft cells in human gastro-intestinal and pancreatic-biliary tract. Scientific Reports 2019;9:17466.

120. McGinty JW, Ting H-A, Billipp TE, et al. Tuft-Cell-Derived Leukotrienes Drive Rapid Anti-helminth Immunity in the Small Intestine but Are Dispensable for Anti-protist Immunity. Immunity 2020;52:528-541.e7.

121. Grondin JA, Kwon YH, Far PM, et al. Mucins in Intestinal Mucosal Defense and Inflammation: Learning From Clinical and Experimental Studies. Front Immunol 2020;11:2054.

122. Sicard JF, Le Bihan $G$, Vogeleer $P$, et al. Interactions of Intestinal Bacteria with Components of the Intestinal Mucus. Front Cell Infect Microbiol 2017;7:387.

123. Pelaseyed T, Bergstrom JH, Gustafsson JK, et al. The mucus and mucins of the goblet cells and enterocytes provide the first defense line of the gastrointestinal tract and interact with the immune system. Immunol Rev 2014;260:8-20. 
bioRxiv preprint doi: https://doi.org/10.1101/2021.10.05.460818; this version posted October 6, 2021. The copyright holder for this preprint (which was not certified by peer review) is the author/funder, who has granted bioRxiv a license to display the preprint in perpetuity. It is made available under aCC-BY-NC-ND 4.0 International license.

124. Pelaseyed T, Hansson GC. Membrane mucins of the intestine at a glance. Journal of Cell Science 2020;133.

125. Ma J, Rubin BK, Voynow JA. Mucins, mucus, and goblet cells. Chest 2018;154:169-176.

126. Jassal B, Matthews L, Viteri G, et al. The Reactome Pathway Knowledgebase. Nucleic Acids Research 2020;48:D498-D503.

127. Cornick S, Tawiah A, Chadee K. Roles and regulation of the mucus barrier in the gut. Tissue Barriers 2015;3:e982426.

128. Layunta E, Javerfelt S, Dolan B, et al. IL-22 promotes the formation of a MUC17 glycocalyx barrier in the postnatal small intestine during weaning. Cell Rep 2021;34:108757.

129. Sun WW, Krystofiak ES, Leo-Macias A, et al. Nanoarchitecture and dynamics of the mouse enteric glycocalyx examined by freeze-etching electron tomography and intravital microscopy. Commun Biol 2020;3:5.

130. Nyström EEL, Martinez-Abad B, Arike L, et al. An intercrypt subpopulation of goblet cells is essential for colonic mucus barrier function. Science 2021;372.

131. Birchenough GM, Johansson ME, Gustafsson JK, et al. New developments in goblet cell mucus secretion and function. Mucosal Immunol 2015;8:712-9.

132. Beumer J, Puschhof J, Bauza-Martinez J, et al. High-Resolution mRNA and Secretome Atlas of Human Enteroendocrine Cells. Cell 2020;181:1291-1306 e19.

133. Billing $\mathrm{L}$, Larraufie $P$, Lewis J, et al. Single cell transcriptomic profiling of large intestinal enteroendocrine cells in mice - Identification of selective stimuli for insulin-like peptide- 5 and glucagon-like peptide-1 co-expressing cells. Mol Metab 2019;29:158-169.

134. Roberts GP, Larraufie P, Richards P, et al. Comparison of Human and Murine Enteroendocrine Cells by Transcriptomic and Peptidomic Profiling. Diabetes 2019;68:1062-1072.

135. Sjolund K, Sanden G, Hakanson R, et al. Endocrine cells in human intestine: an immunocytochemical study. Gastroenterology 1983;85:1120-30.

136. Liddle RA. Neuropods. Cell Mol Gastroenterol Hepatol 2019;7:739-747.

137. Kaelberer MM, Buchanan KL, Klein ME, et al. A gut-brain neural circuit for nutrient sensory transduction. Science 2018;361.

138. Bellono NW, Bayrer JR, Leitch DB, et al. Enterochromaffin Cells Are Gut Chemosensors that Couple to Sensory Neural Pathways. Cell 2017;170:185-198 e16.

139. Worthington JJ, Reimann F, Gribble FM. Enteroendocrine cells-sensory sentinels of the intestinal environment and orchestrators of mucosal immunity. Mucosal Immunol 2018;11:3-20.

140. Gribble FM, Reimann F. Signalling in the gut endocrine axis. Physiol Behav 2017;176:183-188.

141. Egerod KL, Engelstoft MS, Grunddal KV, et al. A major lineage of enteroendocrine cells coexpress CCK, secretin, GIP, GLP-1, PYY, and neurotensin but not somatostatin. Endocrinology 2012;153:5782-95.

142. Habib AM, Richards $P$, Cairns LS, et al. Overlap of endocrine hormone expression in the mouse intestine revealed by transcriptional profiling and flow cytometry. Endocrinology 2012;153:3054-65.

143. Kiela PR, Ghishan FK. Physiology of Intestinal Absorption and Secretion. Best Pract Res Clin Gastroenterol 2016;30:145-59.

144. Gajda AM, Storch J. Enterocyte fatty acid-binding proteins (FABPs): different functions of liver and intestinal FABPs in the intestine. Prostaglandins Leukot Essent Fatty Acids 2015;93:9-16.

145. Dawson PA. Role of the intestinal bile acid transporters in bile acid and drug disposition. Handb Exp Pharmacol 2011:169-203.

146. Dawson PA, Karpen SJ. Intestinal transport and metabolism of bile acids. J Lipid Res 2015;56:1085-99.

147. Agellon LB, Toth MJ, Thomson AB. Intracellular lipid binding proteins of the small intestine. Mol Cell Biochem 2002;239:79-82.

148. Imamura T, Kitamoto Y. Expression of enteropeptidase in differentiated enterocytes, goblet cells, and the tumor cells in human duodenum. Am J Physiol Gastrointest Liver Physiol 2003;285:G1235-41.

149. Zhou FF, Xie W, Chen SQ, et al. SLC38A1 promotes proliferation and migration of human colorectal cancer cells. J Huazhong Univ Sci Technolog Med Sci 2017;37:30-36.

150. Lu Z, Ding L, Lu Q, et al. Claudins in intestines: Distribution and functional significance in health and diseases. Tissue barriers 2013;1:e24978.

151. Kiela PR, Ghishan FK. Physiology of intestinal absorption and secretion. Best Practice \& Research. Clinical Gastroenterology 2016;30:145-159.

152. Camilleri M. Leaky gut: mechanisms, measurement and clinical implications in humans. Gut 2019;68:1516-1526. 
bioRxiv preprint doi: https://doi.org/10.1101/2021.10.05.460818; this version posted October 6,2021 . The copyright holder for this preprint (which was not certified by peer review) is the author/funder, who has granted bioRxiv a license to display the preprint in perpetuity. It is made available under aCC-BY-NC-ND 4.0 International license.

153. Koutroubakis IE. Recent advances in the management of distal ulcerative colitis. World J Gastrointest Pharmacol Ther 2010;1:43-50.

154. Ahmad R, Rah B, Bastola D, et al. Obesity-induces Organ and Tissue Specific Tight Junction Restructuring and Barrier Deregulation by Claudin Switching. Sci Rep 2017;7:5125.

155. Zhu C, Chen Z, Jiang Z. Expression, distribution and role of aquaporin water channels in human and animal stomach and intestines. International Journal of Molecular Sciences 2016;17.

156. Hua S. Advances in Oral Drug Delivery for Regional Targeting in the Gastrointestinal Tract - Influence of Physiological, Pathophysiological and Pharmaceutical Factors. Front Pharmacol 2020;11:524.

157. Thelen K, Dressman JB. Cytochrome P450-mediated metabolism in the human gut wall. J Pharm Pharmacol 2009;61:541-58.

158. Speer JE, Wang Y, Fallon JK, et al. Evaluation of human primary intestinal monolayers for drug metabolizing capabilities. J Biol Eng 2019;13:82.

159. Iswandana R, Irianti MI, Oosterhuis D, et al. Regional Differences in Human Intestinal Drug Metabolism. Drug Metab Dispos 2018;46:1879-1885.

160. Philpott HL, Nandurkar S, Lubel J, et al. Drug-induced gastrointestinal disorders. Frontline Gastroenterol 2014;5:49-57.

161. Wang D, Zou L, Jin Q, et al. Human carboxylesterases: a comprehensive review. Acta Pharm Sin B 2018;8:699712.

162. Ando Y, Saka H, Asai G, et al. UGT1A1 genotypes and glucuronidation of SN-38, the active metabolite of irinotecan. Ann Oncol 1998;9:845-7.

163. Pitot HC, Adjei AA, Reid JM, et al. A phase I and pharmacokinetic study of a powder-filled capsule formulation of oral irinotecan (CPT-11) given daily for 5 days every 3 weeks in patients with advanced solid tumors. Cancer Chemother Pharmacol 2006;58:165-72.

164. Rothenberg ML, Kuhn JG, Schaaf LJ, et al. Alternative dosing schedules for irinotecan. Oncology (Williston Park) 1998;12:68-71.

165. Kumler I, Sorensen PG, Palshof J, et al. Oral administration of irinotecan in patients with solid tumors: an openlabel, phase I, dose escalating study evaluating safety, tolerability and pharmacokinetics. Cancer Chemother Pharmacol 2019;83:169-178.

166. Panes J, Vermeire S, Lindsay JO, et al. Tofacitinib in Patients with Ulcerative Colitis: Health-Related Quality of Life in Phase 3 Randomised Controlled Induction and Maintenance Studies. J Crohns Colitis 2018;12:145-156.

167. Sanders DB, Hart IK, Mantegazza R, et al. An international, phase III, randomized trial of mycophenolate mofetil in myasthenia gravis. Neurology 2008;71:400-6.

168. Kremer JM, Cohen S, Wilkinson BE, et al. A phase IIb dose-ranging study of the oral JAK inhibitor tofacitinib (CP$690,550)$ versus placebo in combination with background methotrexate in patients with active rheumatoid arthritis and an inadequate response to methotrexate alone. Arthritis Rheum 2012;64:970-81.

169. Seyhan AA, Carini C. Are innovation and new technologies in precision medicine paving a new era in patients centric care? J Transl Med 2019;17:114. 
A Goblet Cell Differential Genes

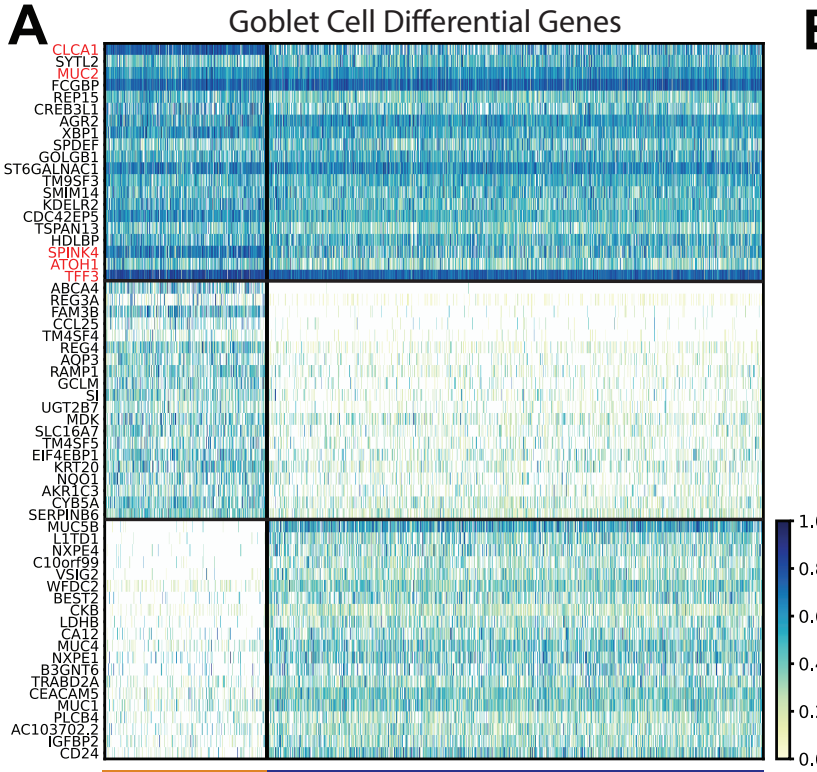

Small Intestine Goblet

Colon Goblet

G

Enteroendocrine Cell Differential Genes

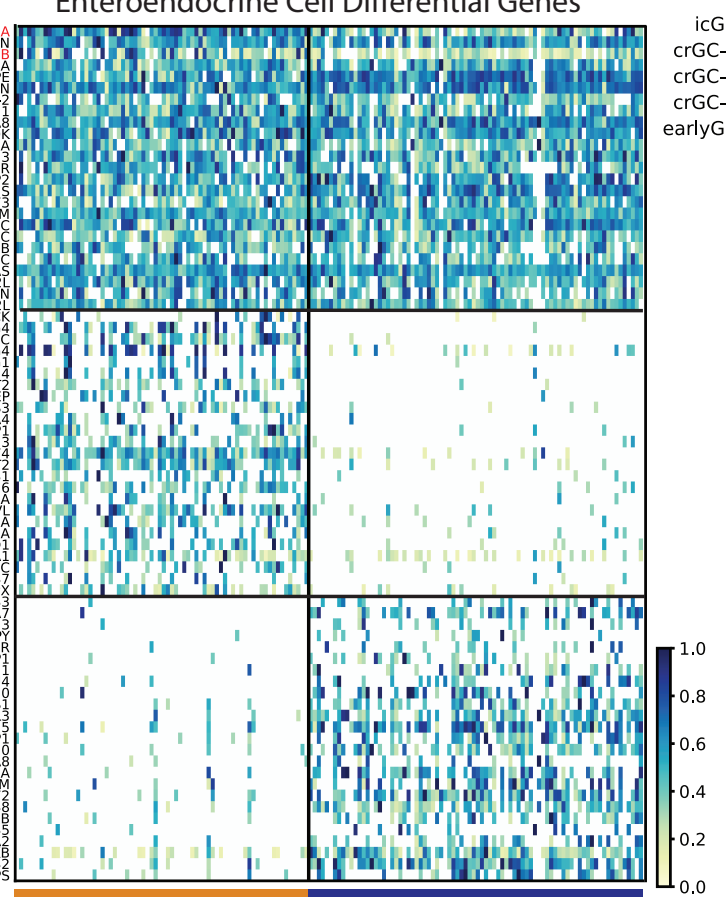

Small Intestine EEC

Colon EEC
B SI and Colon GCs

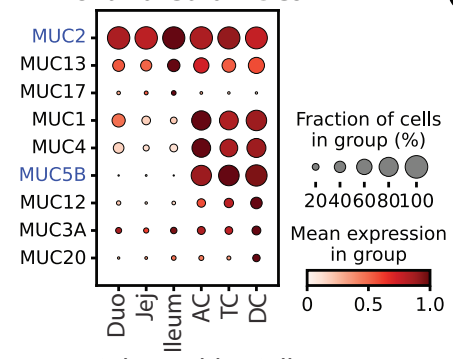

D Colon Goblet Cell

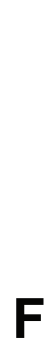

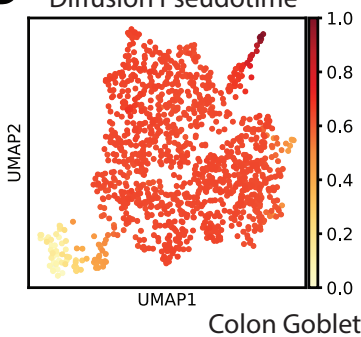

C Colon Goblet Cell Leiden Sub-Clustering

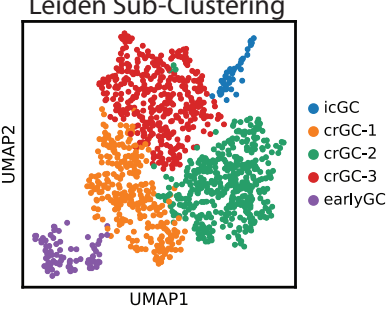

E Colon Goblet Cell

E MUC2 Expression

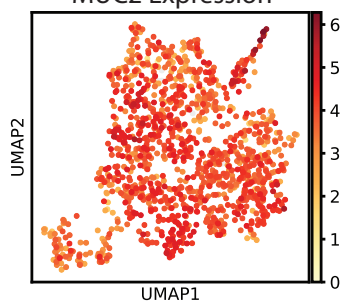

Early Crypt-Resident Classical Goblet Intercrypt Goblet Cells Goblet Cells Cell Markers Goblet Cells

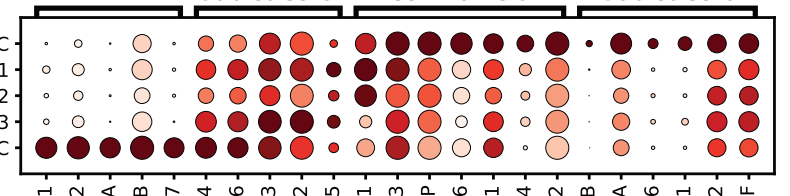

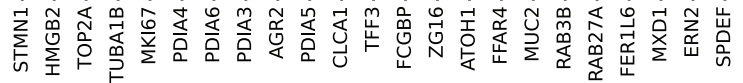

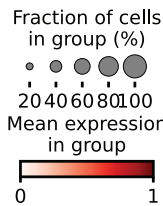

$\mathrm{H}$

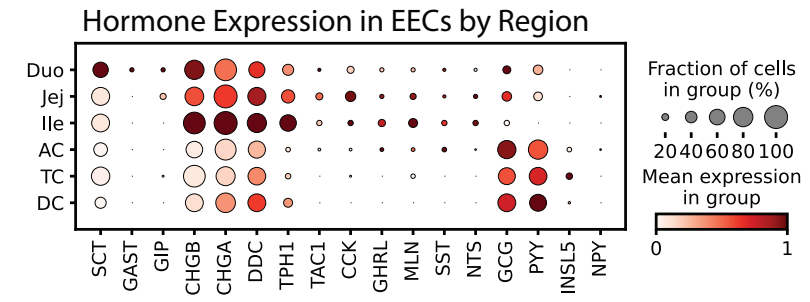

I Select Receptor Expression in EECs by Region

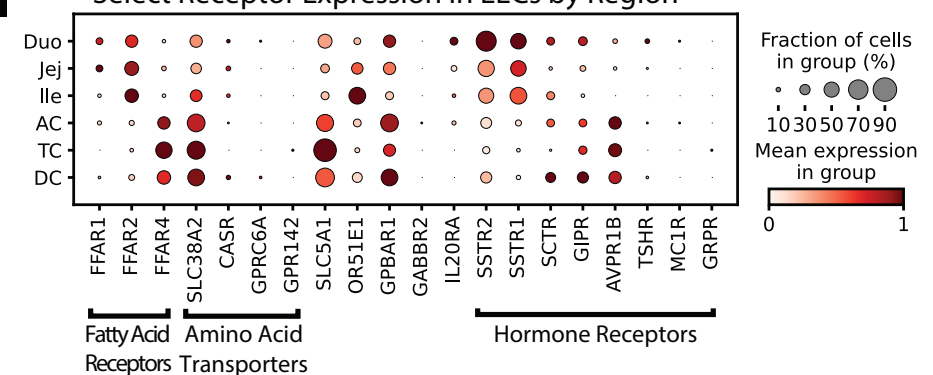

Receptors Transporters

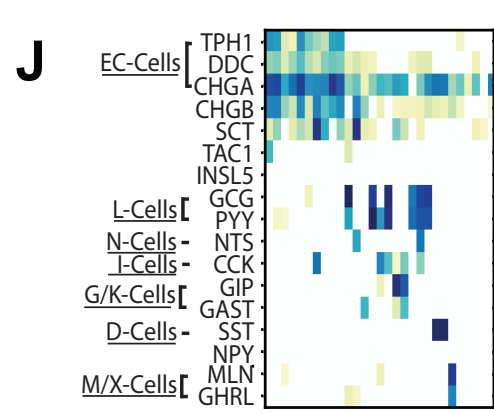

Duo

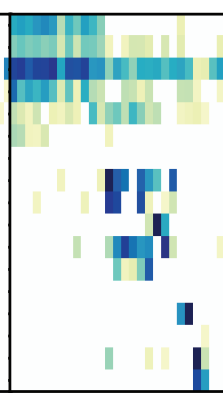

Jej
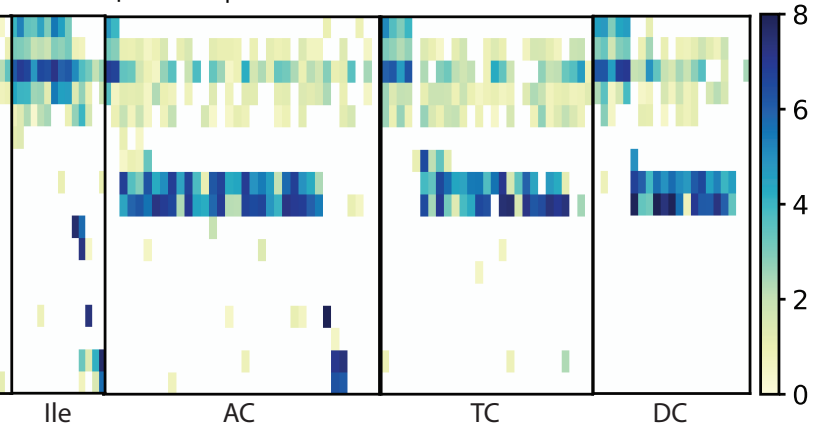
Integrins Receptors

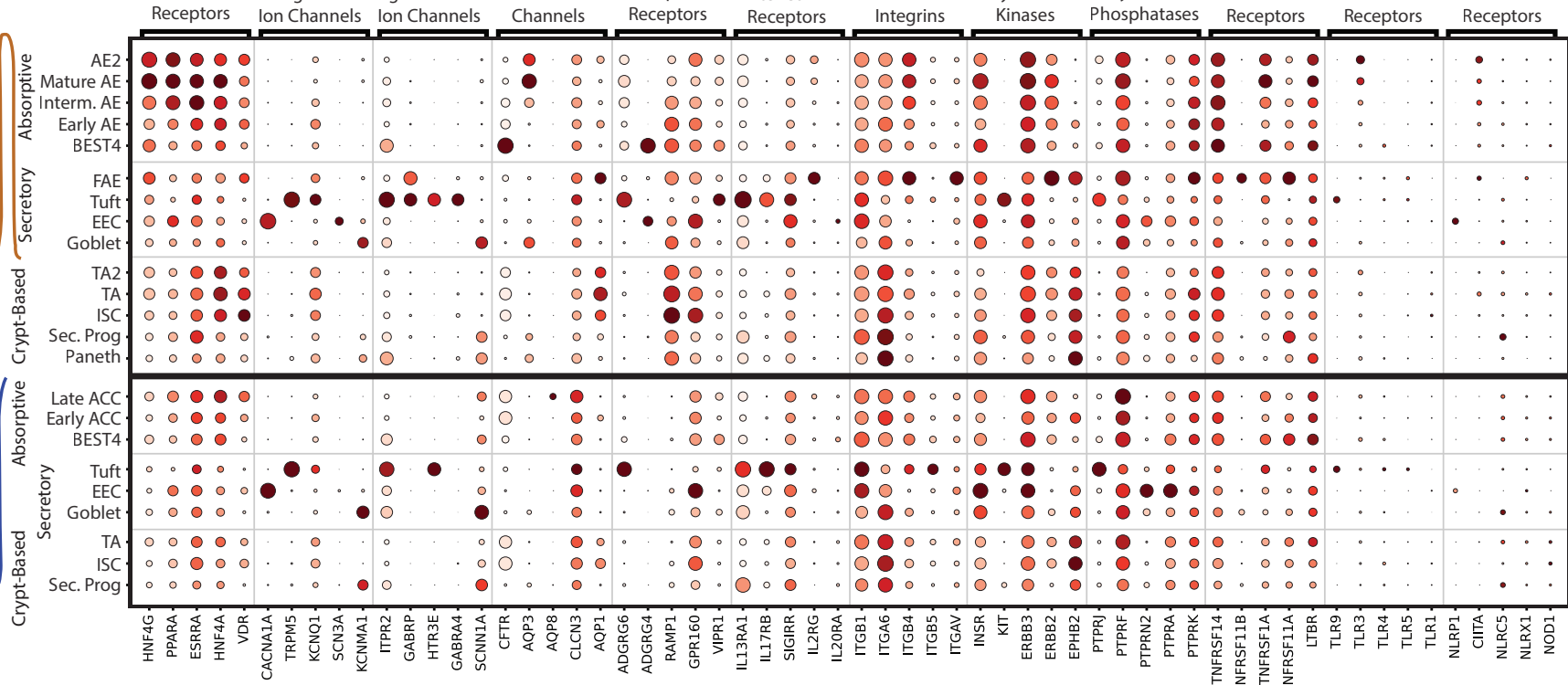

Total Receptors by Cell Type

with Highest Expression
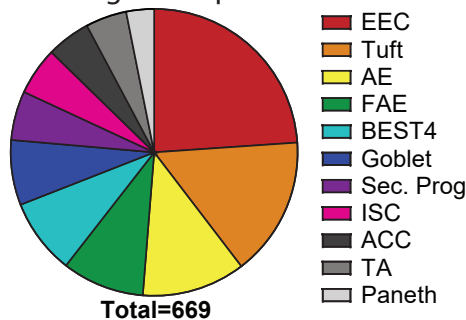

D

Drug

Tacrolimus Function

Mycophenolate Immunosuppressant $\overline{\text { FKBP1A }}$ Mofetil

Tofacitinib Methotrexate Prednisolone Prednisone Natalizumab Vedolizumab

JAK Inhibitor Immunosuppressant DHFR Corticosteroid NR3C1 Corticosteroid Immune Cell Blocker ITGA4 Anti-Inflammatory ITGA4

Patient-Specific Expression of IBD Drug Targets Across all Lineages FKBP1A \begin{tabular}{|llllll|l}
\hline & 0 & 0 & 0 & 0 & 0 & Donor 1 \\
0 & 0 & 0 & 0 & 0 & 0 & Donor 2 \\
0 & 0 & 0 & 0 & 0 & 0 & Donor 3 \\
\hline
\end{tabular} $\mathrm{IMPDH} 2$ $\begin{array}{llllll}0 & 0 & 0 & 0 & 0 & 0 \\ 0 & 0 & 0 & 0 & 0 & 0 \\ 0 & 0 & 0 & 0 & 0 & 0\end{array}$

JAK1

Fraction of cells $\circ \circ \bigcirc \bigcirc \bigcirc \bigcirc$ Donor 1 in group (\%)

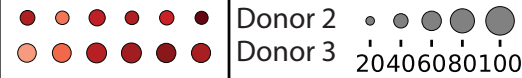
음 $\stackrel{\oplus}{=} \cup \cup$

Donor 1

Donor 2 Donor 3
Primary Targets of Approved Drugs

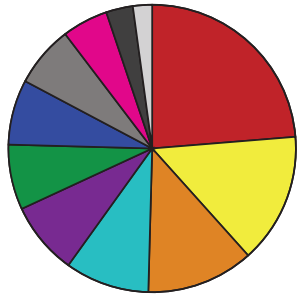

Total Targets $=232$

Total Drugs $=498$
Phase II Drug Metabolism Genes

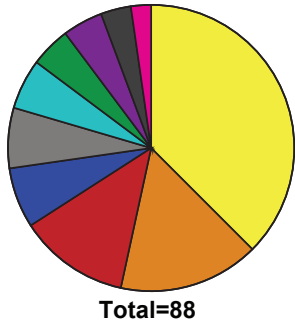

Total $=88$
Metabolism Genes

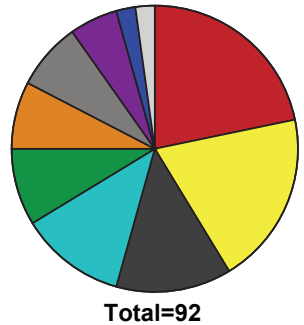

$\square$ EEC $\square$ Tuft $\square$ Sec. Prog. $\square$ Goblet $\square$ ISC $\square \mathrm{AE} \square \mathrm{BEST} 4 \mathrm{FAE} \square \mathrm{TA} \square \mathrm{ACC} \square$ Paneth Mean expression
E High Expressing (Max cluster $>0.5)$
FKBP1A
IMPDH2

Mid Expressing (Max cluster 0.05-0.5)

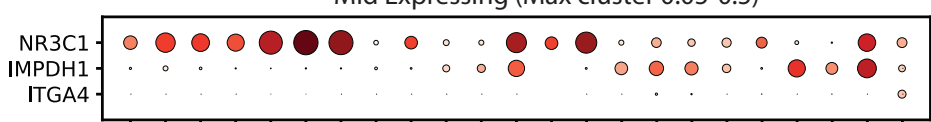

Low Expressing (Max cluster $<0.05$ )

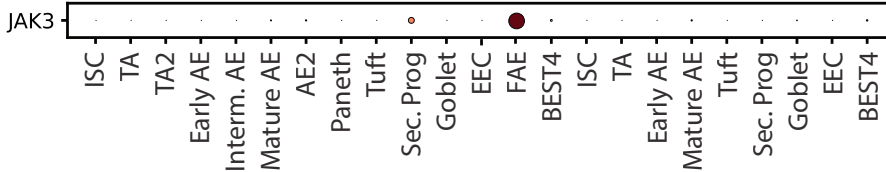

Small Intestinal Lineages
Fraction of cells in group (\%) - 000 20406080100 Mean expression 0.51 .0 of cells

0.0

0.2

Fraction of cells in group (\%)

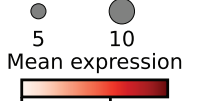

$0.00 \quad 0.02$ 